\title{
EL CENSO DE MANUFACTURAS DE 1784. UNA NUEVA FUENTE PARA EL ANÁLISIS DE LA INDUSTRIA CATALANA *
}

\author{
ISABEL MIGUEL LOPEZ \\ Departamento de Historia é Instituciones Economicas \\ Universidad de Valladolid
}

\begin{abstract}
RESUMEN
El aCenso de manufacturas de 1784n, documento inédito hasta ahora, constituye la fuente utilizada para el acercamiento al sector manufacturero catalán a finales del siglo xvill. A través de él se accede a una imagen global de las actividades de transformación, así como a la delineación del espacio más intensamente afectado por ellas. Pero, sobre todo, posibilita apreciar los contrastes de equipamiento, mano de obra empleada, con. sumo de materias primas o producto obtenido por unas unidades de producción, cuyas caracteristicas nos sitúan ante un periodo de transición en el que se abren paso nuevas fórmulas resquebrajando el orden gremial. Un proceso al que se asiste desde una óptica regional aportando matizaciones a la percepción localista existente sobre el quehacer transformador de la época.
\end{abstract}

\section{ABSTRACT}

The analyse of the 1784 «Censo de Manufacturass represents a sound attempt at understanding the catalonian manufacturing industry at the end of the xvilth Century. This Census offers not only a global picture of the industrials activities, but also the spatial location of the main industrial towns. In addition, this document shows diferences in the productive infrastructure use the labour force employed, the raw materials transformed and the products obtained for productive units. From these I can corroborate that the old guilds were desintegrating. Moreover, a general perspective is offered, thus completing previous studies about local activities.

* Este trabajo es un adelanto del estudio referido a todo el Reino, en avanzado estado de elaboración, que ha dispuesto de la financiación otorgada por la Junta de Castilla y León y por la DGCYT a los proyectos «Fuentes documentales y testimonios materiales para la industria en Castilla y León (1750-1970) y PB 93-0223, respectivamente. Asimismo, expreso mi gratitud a Ángel Garcia Sanz, Juan Helguera, Josep Maria Benaul y Alejandro Sanchez por sus observaciones y sugerencias.

Revisa de Historia Económica

Año XIV. Invierno $19 \%, N * 1$ 


\section{INTRODUCCIÓN: LA FUENTE DOCUMENTAL}

Lus objetivos económicos de los gobiernos ilustrados incluian, entre otros, el desarrollo del sector transformador para responder a la demanda interna y captar el mercado americano. Precisamente, la finalidad de «fomentar y proteger las manufacturas e industrias en estos Reinosm, a partir de un mejor conocimiento de la realidad, fue el móvil de la Junta General de Comercio cuando, en diciembre de 1783, decidió elaborar una «Razón sobre el estado de las fábricas y de los estorbos y medios de vencerlosm, mediante una Encuesta que se envió a los Intendentes y a los Administradores de Rentas Provinciales, ya que se advirtió que la combinación de noticias obtenidas por ambas vias proporcionaria una mayor fiabilidad. Las respuestas a las cuestiones planteadas por la Institución relativas al número de fábricas en las distintas variedades de tejidos, sombreros, estampación, curtidos, loza, papel, jabón, martinetes y ferrerias, lona, jarcia y cordeleria, esparto o "cualquier otro ramo de la industria o producción útiles al comercio y fábricasm, asi como las referidas a las condiciones técnicas en que se desarrollaba la producción, al equipamiento, las materias primas utilizadas («añadiendo la noticia de si el algodón ... se hila en el pais o se introduce hilado de fuera del Reynom), la mano de obra empleada y su productividad, la producción obtenida y sus clases, señalando en los establecimientos de «alguna consideracion», el nombre de sus dueños, configuran el contenido de lo que denominamos Censo de Manufacturas de 1784 ' ya que la mayor parte de la información fue recibida en Madrid durante ese año.

La contestación del Principado de Cataluña a los interrogantes utilizó las dos vias previstas, la del Intendente que envió su informe original a la Junta General de Comercio y la del Administrador General de la Aduana de Barcelona, Juan José Oteiza, que remitió los resultados de las pesquisas a la Dirección General de Rentas, en junio de 1785, en seis cuadernillos de papel, encabezados como Relación de Manufacturas, artes, oficios e industria de los pueblos del Principado de Cataluña con distinción de subdelegaciones y arreglo a lo que resulta de las noticias dadas por sus justicias y ayuntamientos. Esta «Relación», inédita hasta ahora, contribuye a ocupar un vacio en la información cuantitativa global referida a la industria catalana durante el último cuarto del siglo XVIII, aun cuando falten noticias de ciertos núcleos (Alto Ampurdán) o se desearan más explicitas sobre otros como Sabadell. No obstante, destaca su carácter sistemático, la amplitud del espacio geográfico y de los subsectores encuestados respecto a otras fuentes de los años 80 como el Censo de Artalejo sobre el Obispado de Vic,

'Archivo General de Simancas, Direccion General de Rentas, II Remesa, legs. 497 y 503. 
los Diarios de Viajes de Francisco Zamora o sus Interrogatorios, situándose, cronológicamente, entre las Estadísticas de 1760/61 y 1760/65, centradas en el sector lanero, y las informaciones recogidas a principios del siglo xIX. El valor del documento se consideró significativo por cuanto, en 1790, se le utilizó de referencia al preguntar al Administrador de la Aduana de la ciudad condal sobre la variación producida en las fábricas con respecto a la Relación de 1784. El presente trabajo pretende proyectar la imagen elaborada mediante los diversos aspectos captados por los testimonios registrados.

\section{DIVERSIDAD MANUFACTURERA Y LOCALIZACION ESPACIAL}

El análisis de la información que proporciona el Censo de Manufacturas de 1784 permite captar la complejidad del sector transformador catalán derivada de la multiplicidad de actividades que incluye pero también de la variedad de circunstancias en las que se obtiene la producción, en las que se combina la tradición con la innovación en respuesta a los nuevos requerimientos del mercado. En el extenso abanico de quehaceres es perceptible desde el principio la prioridad de la industria textil, como, por otra parte, sucedía en el resto de España. Una apreciación confirmada por el indicador del empleo, con las necesarias reservas que su utilización implica por el recurso al trabajo a tiempo parcial. Ocupaba en torno al 95 por 100 del total de la mano de obra contabilizada, que superaba ligeramente las 57.000 personas ${ }^{2}$, predominando la manufactura de la lana, seguida del algodón, seda y, más lejos, del lino/cáña. mo ${ }^{3}$. En este sentido, el trabajo de la lana es expresivo de la especialización en una sola fibra, ya que 42 de los 69 pueblos en los que se registra actividad lanera se dedican solamente a ella, casi todos entre 500 y 1.000 habitantes, a excepción de Castelltersol, Monistrol de Monserrat, Moia y Tarrasa que estaban más poblados, $y$ entre los otros 27 sobresale la combinación con algodón, de modo que lana/seda/algodón se elaboraban en Barcelona, Manresa e Igualada, lana/lino/algodón en Berga, Ripoll y San Feliu de Torelló, triadas significativas de la evolución posterior junto a lino/seda/algodón de Mata-

\footnotetext{
2 La contabilización a partir del Censo de 1784 es muy superior a las 37.817 personas definidas en el Censo de Floridablanca y está más en consonancia con lo calculado por Benavente y Nicolau i Nos (1990), p. 47, para una década más tarde, a partir del Censo de 1797 en el que se anotan 57.453 individuos ocupados en el sector secundario catalán.

'Se registraban 17.673 personas dedicadas a la lana, 14.864 al tejido de algodón, 14.623 a la seda y 5.829 al tejido de lino/cánamo.
} 
ró y frente a lana/lino/seda en Reus. Otras exclusividades más limitadas tenían lugar con la seda en Tortosa, el algodón en Prats de Rei y el lino en Villafranca, Santa Coloma de Queralt, Santa Coloma de Farnés, por oposición a la utilización de las cuatro fibras en Vic y Manresa.

La hilatura y tejeduría de lino y cáñamo, relativamente dispersa por el territorio catalán, encontraba en las tierras de la actual provincia de Barcelona el mayor número de telares (Villafranca, Mataró y Vic), aunque fueran Reus o Santa Coloma de Farnés las que dispusieran de la concentración más elevada por localidad. Entre tanto, el ámbito drenado por los afluentes del Llobregat, el Ter medio y la cabecera del Fluviá constituyeron el asentamiento preferente de la mayor parte de la transformación relacionada con la lana, destacando las localidades de Tarrasa, Igualada y Olot, de modo que, fuera de él, resultaba espóradica esta maniobra, pues sólo Reus ofrecía alguna actividad asi como el corregimiento de Salas, Montella y Martinet o la Villa y Bailia de Bellver ${ }^{4}$. Mientras, el arte de la seda se polarizaba en Barcelona y Manresa, que acogian el 85 por 100 de los telares a ella dedicados, seguidas de los enclaves de Reus o Valls. Por su parte, el trabajo del algodón giraba en torno a la ciudad condal que concentraba el 90 por 100 de los telares de indianas y proporcionaba más de la mitad del conjunto de tejidos de algodón del Principado. Tras ella, Olot, Manresa, Mataró, Igualada/Capellades, Berga, Puigcerdá delimitaban un área que se deslizaba hacia el litoral con pequeños núcleos, si bien reforzaba enclaves laneros y sederos. Simultáneamente, la obtención de sombreros corroboraba el espacio textil de Barcelona, Igualada y Reus (Mapas I-A y I-B y Apéndices I-V).

$\mathrm{El}$ análisis del subsector más significativo proporciona una trama industrial sobre el espacio que se ve consolidada por otras actividades manufactureras. Tal es el caso del trabajo del cuero cuyos núcleos más notables se ubicaban en algunos de aquellos que también lo eran en quehaceres textiles. Así ocurría en Barcelona, Vic, Olot, Igualada, y en menor medida en Reus y Valls, con la nota sobresaliente de Horta's Localidades que merecen resaltarse por el número de sus tenerias, el empleo movilizado y la variedad de sus productos. Sin

- Destacarian las Subdelegaciones de Manresa,Vic y Mataró, lo que coincide en lineas generales con las zonas II y V diseñadas por T'orras (1984), p. 120, y por Benaul (1991), p. 100, aunque se aprecia en el Censo de 1784 una disminución del numero de pueblos que declararon su relación con esta actividad. En Sabadell sólo se indica que existian 10 fábricas de paños 32nos y 30nos.

s Torras i Ribé (1991), p. 44, y (1994), p. 302. El Censo de 1784 recoge información sobre Salas pero no se cita curtido en Tremp y tampoco ninguna noticia sobre el mismo en Gerona, centros destacados en la obra de este autor. Con relación a la tenería-museo de Igualada Enrich y otros (1990), passım. 

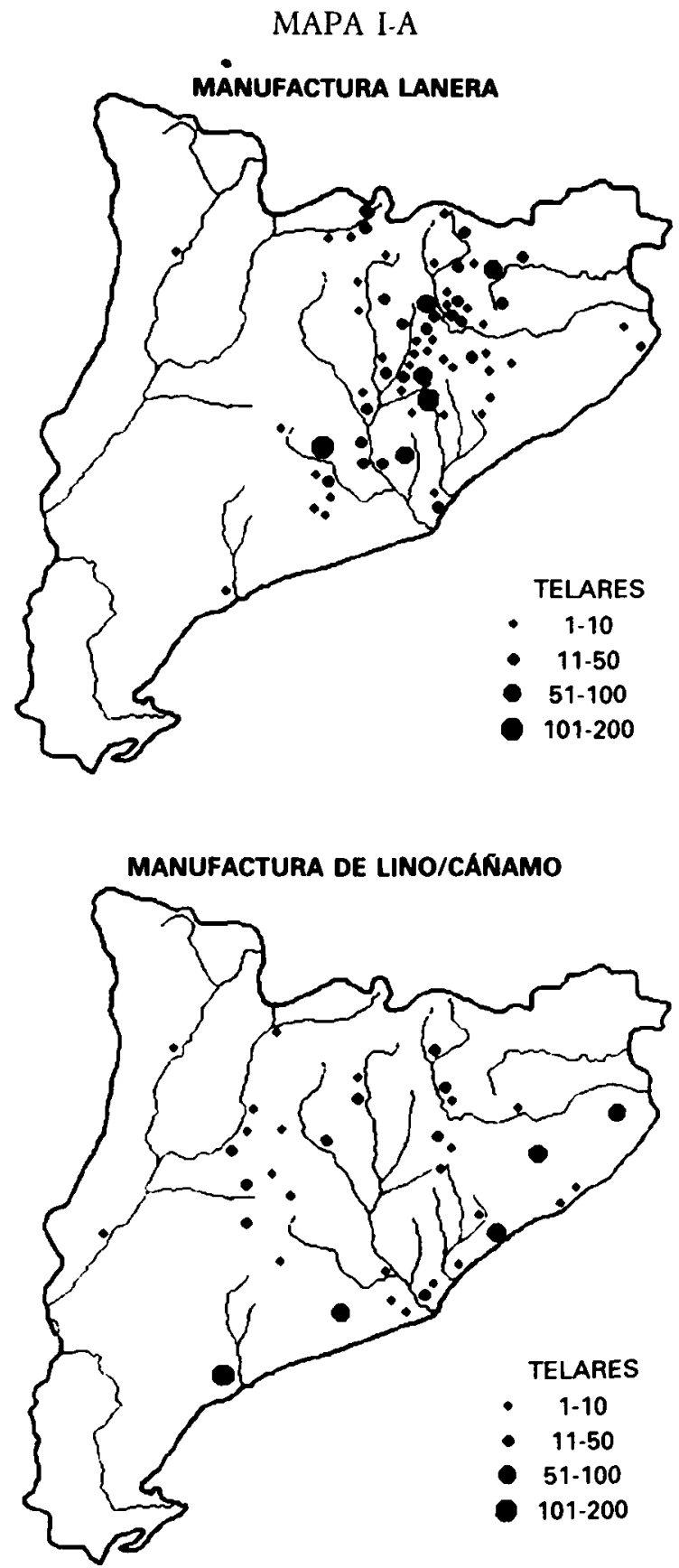

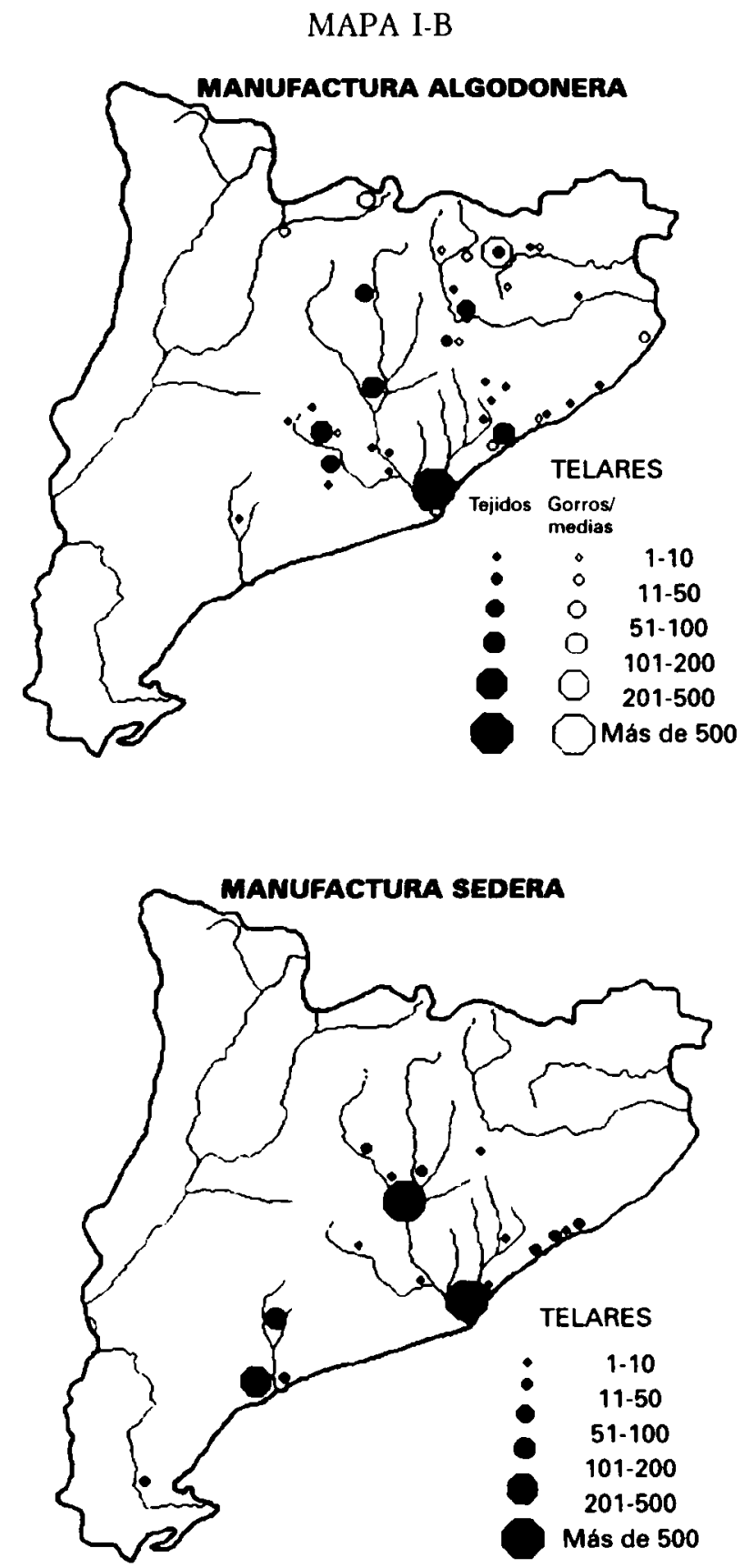
embargo, el espacio del curtido se abría hacia el oeste leridano donde sólo se habían mencionado algunas labores de lino/cañamo, de igual forma que sucedía en La Bisbal, pero a diferencia de San Cristóbal de Capdevañol y Xerta que no tenian relación con el textil (Mapa II y Apéndice VI).

Tras la estela de tejidos y curtidos la obtención de papel constituia otro de los subsectores más destacados del Principado, donde se anotaban 95 molinos, aunque con la falta de cuantificación de Torre de Claramunt ${ }^{6}$. La mayor concentración se localizaba en La Riba, fuera de las áreas con máxima densidad textil, si bien próxima a la linera, sedera y curtidora Reus, en tanto que otros enclaves con la mitad de molinos, como Capellades, San Pedro Riudevitllas, futuros emporios papeleros, y Olot estaban emplazadas en zonas ya valoradas por las actividades mencionadas, en pos del trapo y la carnaza, materias primas papeleras básicas ${ }^{7}$ (Apéndice VII).

En los intersticios de la trama industrial observada se situaba la fabricación de loza. San Juan de Vilatorta, Reus o Lérida sobresalian claramente entre los censados, desviando, por lo que a estas dos últimas se refiere, la gravitación industrial de las tierras barcelonesas (Apéndice VIII). Un hecho que vuelve a observarse en las referencias a la manufactura de vidrio, localizada en Alfara, pero se trataba de una instalación, vinculada a la Compañia de Vitalicios de Barcelona, que estaba parada en 1784 .

El espacio industrial ocupado por textil y cuero e incluso papel, se refuerza si se consideran oficios como la elaboración de jarcia, cordelería y manufactura de esparto que ofrecían cierto dinamismo ante la expansión naval. Se registraba en localidades costeras o próximas a la costa (Calella, Arenys de Mar, Badalona, Mataró, San Feliu de Guixols, Gava, Hospitalet, Granollers, Tarragona, Reus) o cercanas a las materias primas requeridas (Vic, Calaf, Cervera, Guissona) que lanzan tímidamente de nuevo alguna pulsión del sector transformador hacia el occidente del Principado (Apéndice IX). Este movimiento occidental se confirma por la producción de jabón en las localidades de Arbeca, Borjas Blancas, Cervera, Solsona o la propia ciudad de Lérida. No obstante, la mayor productora era Mataró, aunque las tierras tarraconenses alojaran buena parte de las calderas en funcionamiento (Apéndice X). La disponibili-

"Cantidad muy alejada de los 160 que para 1785, un año después, indica Delgado (1983), p. 727 , y que supondria un extraordinario crecimiento en relación a los 109 de 1775 , Gutiérrez i Poch (1994), p. 347

Gutiérrez i Poch (1988), pp. 354.356, y (1993), passim.

* Habia iniciado la construcción de artefactos en 1782, aunque en 1783, según R.O. de 26 de febrero, se le privó del aprovechamiento de leñas de los montes de su entorno y ello, al parecer, le obligi a parar. 


\section{MAPA II}

Localización de algunas actividades transformadoras

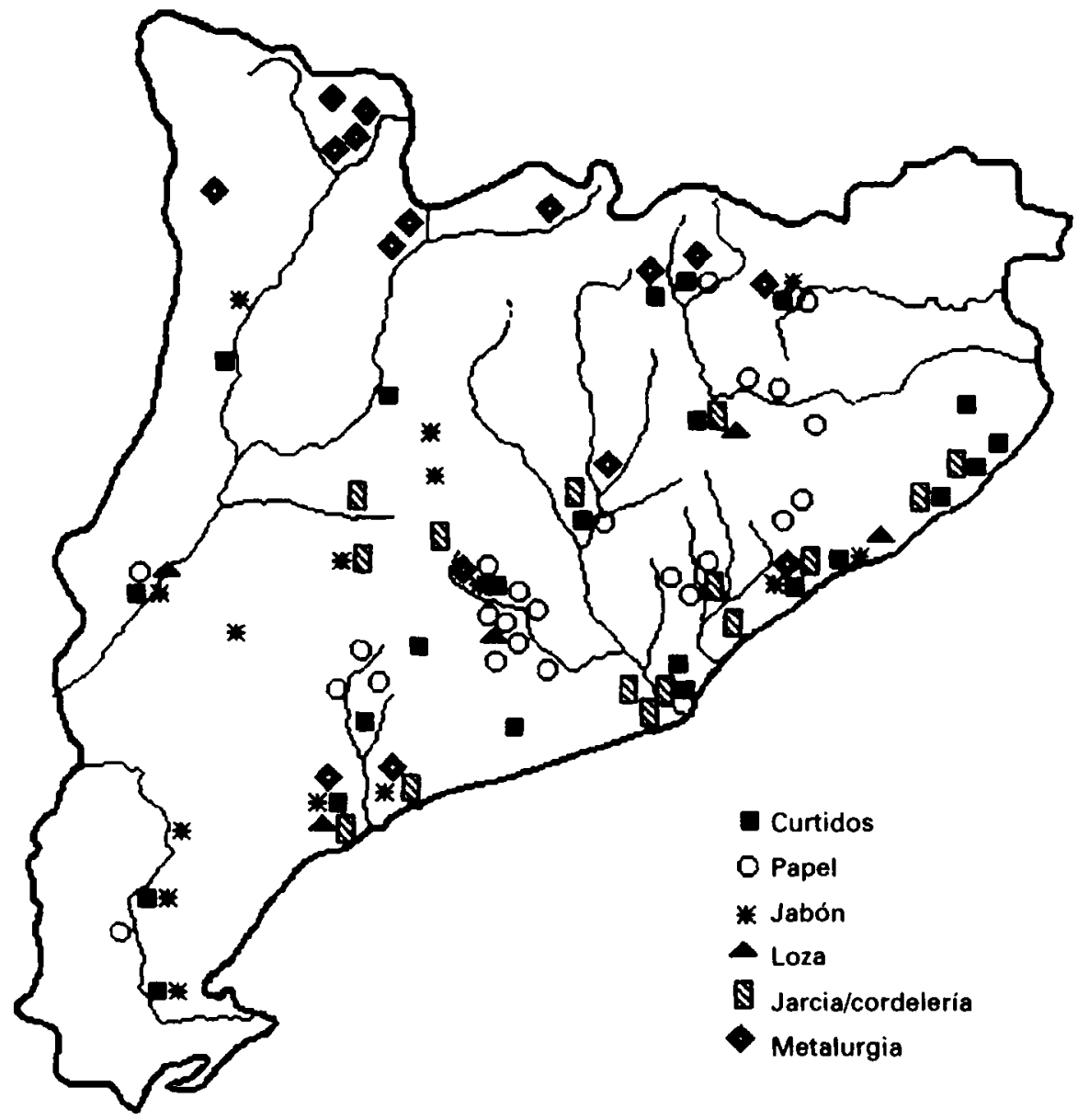


dad de aceite de oliva y la posiblidad de obtener el alcali con cierta facilidad explicarian esas localizaciones occidentales, periféricas al tejido industrial central, en una manufactura que tarda en salir de los horizontes familiares 9.

$\mathrm{El}$ área afectada por el quehacer manufacturero en la geografía catalana se amplía al considerar el subsector metalúrgico. Las fargas, establecidas en el Pirineo leridano (Arcabell, Noves, Aynet, Alins, Llavorsi) y gerundense (Ripoll, San Cristóbal de Capdevañol), en relación con las materias primas necesarias ${ }^{10}$, se alejaban de los centros industriales aludidos, excepto por lo que respecta a las localidades de Olot y Ripoll que acogian la mayor diversidad de metalurgia de transformación (Apéndice XI). En la capital de la Garrotxa, junto a un martinete, el despliegue se debia a la presencia de múltiples artifices entre los que se encontraban maestros cuchilleros, latoneros, un fabricante de tijeras de tundir, Bernardo Planas, «único en su especie en toda España, según se cree», otro de agujas para los tejidos de algodón y cinco familias que construian cardas. En Ripoll, además de la farga y el martinete, se habían instalado fabricantes de cañones, de llaves de fusiles y pistolas, de encepadoras y de clavos para navios. Fuera del ámbito pirenaico, Sallent disponia, junto a dos martinetes propiedad de José Fidel de Senillosa, vecino de Barcelona "1, de una fábrica de hilo de latón, Igualada acogía a numerosos fabricantes de armas de fuego y un calderero y en Mataró se habian instalado 5 fábricas de anzuelos y agujas ${ }^{12}$, en tanto que Reus registraba la presencia de varios herreros al igual que Tarragona ${ }^{13}$.

En el conjunto de las actividades recogidas, la agroalimentaria tuvo su mejor exponente en la elaboración de aguardiente, ya que las alusiones a la molinería sólo se encuentran en Gava y Martorell. La destilación estaba polarizada en las localidades de la subdelegación de Manresa ${ }^{14}$, de forma que únicamente Igualada, Capellades, Salas y Reus abrían ese perimetro. Asimismo, sorprende la tipificación de datos, empleo y producción por unidad de fábrica que se repiten sistemáticamente y que parecen responder más a un estereotipo de respuesta que a la realidad, roto únicamente por los núcleos localizados fuera del área manresana (Apéndice XII). Otras manufacturas más esporádicas, pero sig-

- Ramón i Muñoz (1994), pp. 28-29.

${ }^{10}$ Maluquer de Motes (1984), passim.

11 Benet i Clara (1988), p. 340, y (1989), pp. 54-60.

12 Eran Salvador Simón. Francisco Buigas y Antonio Gual, de mayor relieve; Baltasar Perris, de menor alcance, y Pedro Gual, que obtenia 1000 anzuelos y «bastantes agujas consumiendo $6^{\circ}$ quintales de hierro.

"Para diversos pormenores cuantitativos sobre este subsector, ver Apéndice XI. Actividad industrial de Ripoll: Graells (1972 y 1990, passim)

it Sobre este aspecto, Torras (1984), pp. 116-117. 
nificativas, reforzarian el tejido industrial esbozado. Tal es el caso de la fabricación de barriles y de la industria corchotaponera. La primera se hallaba representada por San Feliu de Guixols y Reus ${ }^{15}$. Por lo que respecta a la segunda, el aprovechamiento del corcho estaba radicado en el nordeste del Principado, San Feliu de Guixols, Palafrugell y La Bisbal ${ }^{16}$. A todos los oficios enunciados se añadiría la fabricación de naipes por Antonio Dutrem, en Olot ${ }^{17}$, donde también se realizaba el pintado de camas con perfiles dorados y esculturas asi como la fabricación de telares de medias, que se verificaba igualmente en $\mathrm{Ri}$ poll (propiedad de José Bajerias), la relojería de Igualada y Olot y la fabricación, en Gava, de muelas para amolar cuchillos.

Así pues, no había subdelegación, excepto la de Arán, en la que no se constatara alguna actividad transformadora, al menos textil, aunque es evidente, tras el recorrido por el Censo, que, más allá de los valles que confluyen en torno a Barcelona y del curso medio del Ter, la dedicación a este sector se debilitaba notablemente, con las excepciones fuera de este ámbito, de Olot y Reus, hasta llegar al vacio industrial del valle leridano ${ }^{18}$. La combinación de la gama de manufacturas indicadas y su localización espacial preferente permite detectar los principales enclaves industriales de Cataluna en estrecha relación con las áreas definidas y sus ocupaciones a finales del siglo xviII (Cuadro 1). De las localidades en las que se ha podido apreciar más dedicación al sector secundario, Tarrasa, la más pequeña, destaca por la exclusiva especialización textil lanera (más del 60 por 100 de sus habitantes están vinculados a ella), en tanto que Olot y Reus muestran la mayor diversidad, que en Olot, con menos población, implicaría añadir otras actividades no especificadas en el cuadro (fabricación de naipes, de telares de medias, pintura de camas doradas), lo que la convertiría en uno de los núcleos más dinámi$\cos { }^{19}$. En menor medida puede apreciarse diversidad en Igualada, Manresa y Mataró, mientras Barcelona se vuelca sobre el textil y el curtido junto a un oficio de calidad como la platería ${ }^{20}$.

15 En San Feliu se declaraban 30 casas de duelas y barriles para sardinas y anchoas que ocupaban a 70 hombres. En Reus existian 197 cuberos que fabricaban más de 12.000 pipas y 30.000 barriles.

16 San Feliu disponia de 40 establecimientos que empleaban a 130 hombres y obtenian 1.000 tapones/hombre/dia. En Palafrugell funcionaban 14 y en La Bisbal 2.

17 Obtenia anualmente 7.920 naipes finos y ordinarios, empleando a 3 personas.

${ }_{18}$ En los pueblos del valle de Arán «no hay fábrica ni industria alguna y sus lanas que no son de mala calidad pasan en bastante porcion a Francia y las restantes se emplean en paños y ropas muy ordinarias por defecto de no saberse hilar».

19 Lluch (1981), passim.

20. El gremio de plateros integraba a 200 maestros y 150 mancebos. 


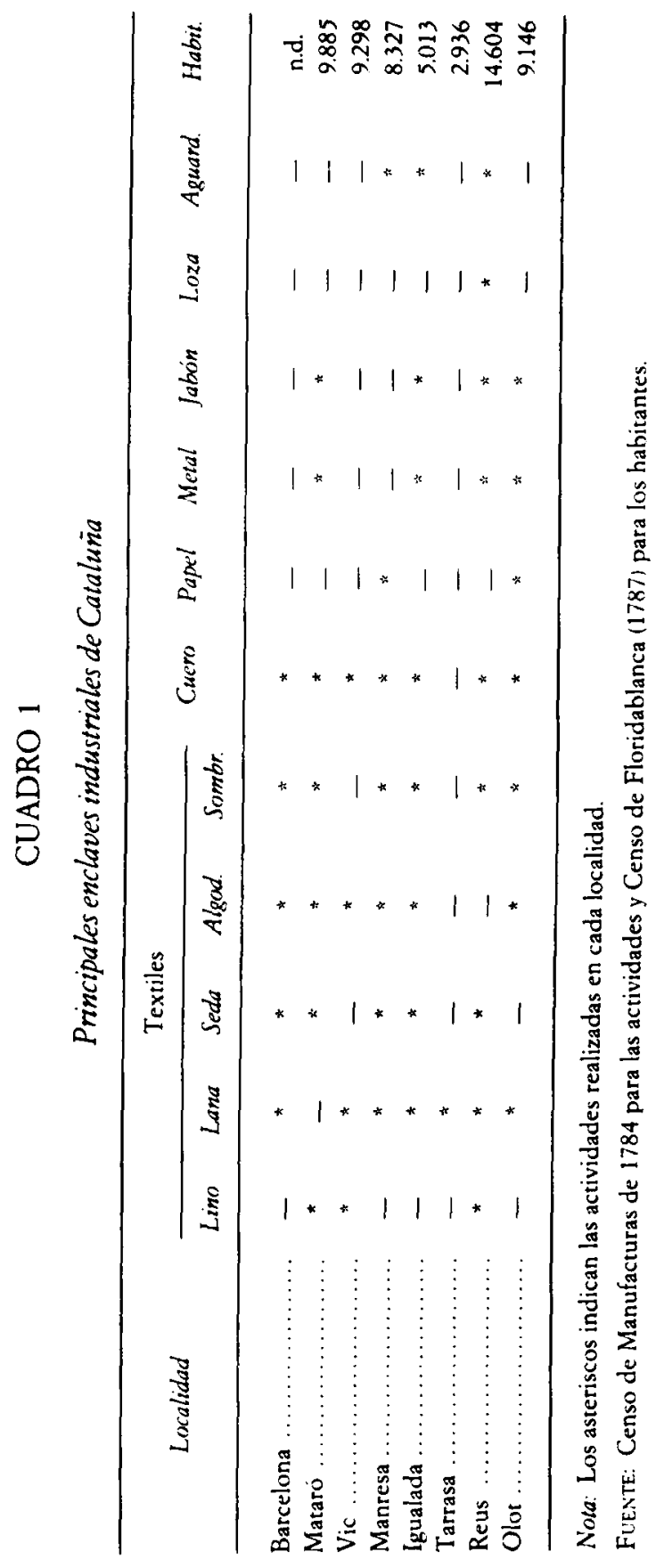




\section{UNIDADES DE PRODUCCIÓN}

La actividad industrial catalana se desarrollaba en unidades de fabricación que incluían domicilio familiar con diversa funcionalidad en la elaboración manufacturera, obrador gremial y «fábrica» que controlaba las etapas del proceso productivo, concentrara o no todas las operaciones en un mismo espacio físico ${ }^{21}$. Esta estructura implicará rasgos específicos en la utilización de los factores de producción, para cubrir un horizonte de consumo que iba desde la propia familia, pasando por los vecinos del pueblo hasta el mercado alejado, respondiendo en este caso más a las directrices del capital comercial y a los intereses de los nuevos empresarios industriales.

\subsection{Del anonimato a la individualidad empresarial}

Se aprecia, al recorrer los datos de este Censo, cómo buena parte de los artifices de la producción pertenecian a un colectivo cuyos nombres no resultaba significativo mencionar porque el volumen del producto que proporcionaban o el método de su obtención no salia de lo considerado habitual/tradicional por quien recogia la información. En el ámbito rural eran los productores domésticos, quienes atendian las necesidades propias y de sus vecinos o se integraban en un proceso de fabricación más amplio dedicándose a operaciones preparatorias intensivas en trabajo y convirtiéndose en unidades de producción subordinadas a intereses ajenos. Tal era el caso del hilado y la tejeduría del lino/cáñamo, asi como el hilado de la lana, seda y algodón, en tanto que el tejido y acabado de estas tres últimas fibras presentaban ya la huella más directa de las individualidades empresariales que se desmarcaban del orden gremial, aun perteneciendo a él, e introducian nuevas formas y relaciones de producción ${ }^{22}$. El resquebrajamiento corporativo puede rastrearse en ciertos fa. bricantes de telas de lino/cáñamo que ponian una nota de modernidad en su elaboración (Cuadro 2), si bien en la fase del hilado de lino debe mencionarse la «fábrica» de Vicente Plä, en Agramunt ${ }^{23}$, que combinaba la hilatura de éste con la del algodón o a los cuatro fabricantes de hilo de cáñamo y lino de Reus ${ }^{24}$. No obstante, será en el tejido de la lana, del algodón y, en parte, de la seda, donde se decante más la transformación de la gestión de las unidades de producción.

\footnotetext{
21 Torras (1987), pp. 155.158.

22 Molas (1970), pp. 74, 201-210.

23 Badosa i Coll (1984), p. 348, le define como comerciante que hace incursiones en la fabricación de gorros y medias de algodón.

24 Estos cuatro fabricantes consumian 45 quintales de cánamo y 125 de lino al año, ocupando a 1.214 personas. Cada libra de lino arendian de 13,5 a 14 sueldos y la de cañamo 12 sueldos.
} 


\section{CUADRO 2}

Fabricantes de tejidos de lino y cáñamo

\begin{tabular}{lllccc}
\hline Localidad & \multicolumn{1}{c}{ Empresario } & Producto & Telares & $\begin{array}{c}\text { Producción } \\
\text { (piezas/año) }\end{array}$ & Empleo \\
\hline Vic & Jaime Lluch & Lienzos cánamo & 12 & - & 1.774 \\
Vic & $\begin{array}{l}\text { José Frco. Llusia/Antonio } \\
\text { Musach/Antonio Mas }\end{array}$ & Lienzos cánamo & 24 & - & 1.640 \\
Mataro & Jaime Carbonell & Lona y loneta & 42 & 1.152 & - \\
Mataró & Ignacio Janer/José Vigas & Lona y loneta & 10 & 240 & - \\
Mataró & M. $^{2}$ Baltasar Viza & Cintas de hilo & 2 & $41.500 \mathrm{v}{ }^{*}$ & - \\
Villafranca & Manuel Virgilles & Medias & - & - & 350 \\
\hline
\end{tabular}

* «v» equivale a varas.

Futerte: Censo de Manufacturas de 1784.

Asi, los trece empresarios laneros de Tarrasa, que desmantelaron la organización gremial y consolidaron la estructura del siglo siguiente, destacaban por su dirección de la fabricación, disponiendo de un nutrido equipamiento y controlando un elevado número de trabajadores (Cuadro 3). Algunos como Gali, Font y Busquets se acercaban por el volumen de empleo a una gran empresa, aunque ésta no concentrara fisicamente todas las fases de producción, y los Font, así como las firmas Gali, Sagrera y Viñals habian progresado notablemente desde 176325 . Además, mostraban una preocupación por los gustos del mercado, en cuanto que los tintes que daban a sus tejidos eran los que les pedian los compradores «imitando las muestras que estos les entregan» y se decantaban por los paños de calidad (Font, Busquets), seguidos de cerca por las bayetas 26nas (Gali). Hasta en una localidad pequeña, San Quirce de Basora ( $973 \mathrm{hb}$.). se transmite la imagen de un nuevo talante empresarial como el de José Viñas y Juan Castán que desempeñaban una labor de producción equiparable a la de ciertos empresarios de Tarrasa aunque en ropa estrecha (Cuadro 4). De forma más esporádica, se encuentran referencias a otros fabricantes destacados de la manufactura lanera como Francisco Camprodón dedicado, en Taradell, a la obtención de monfores, - Lorenzo Valls y Compañia en San Lorenzo Savall, que elaboraba paños entre 26 nos y 36nos asi como bayeta 26 na. Incluso entre los 300 pelaires de Olot dedicados al tejido de medias de lana, se individualizaban como sobresalientes los establecimientos de Esteban Igosa, Mateo Fábrega, Juan Fábrega, Esteban Giral y Jaime Mirambel que desbordaban los límites del gremio.

\footnotetext{
2s Benaul (1992), p. 46 (1991), p. 166.
} 


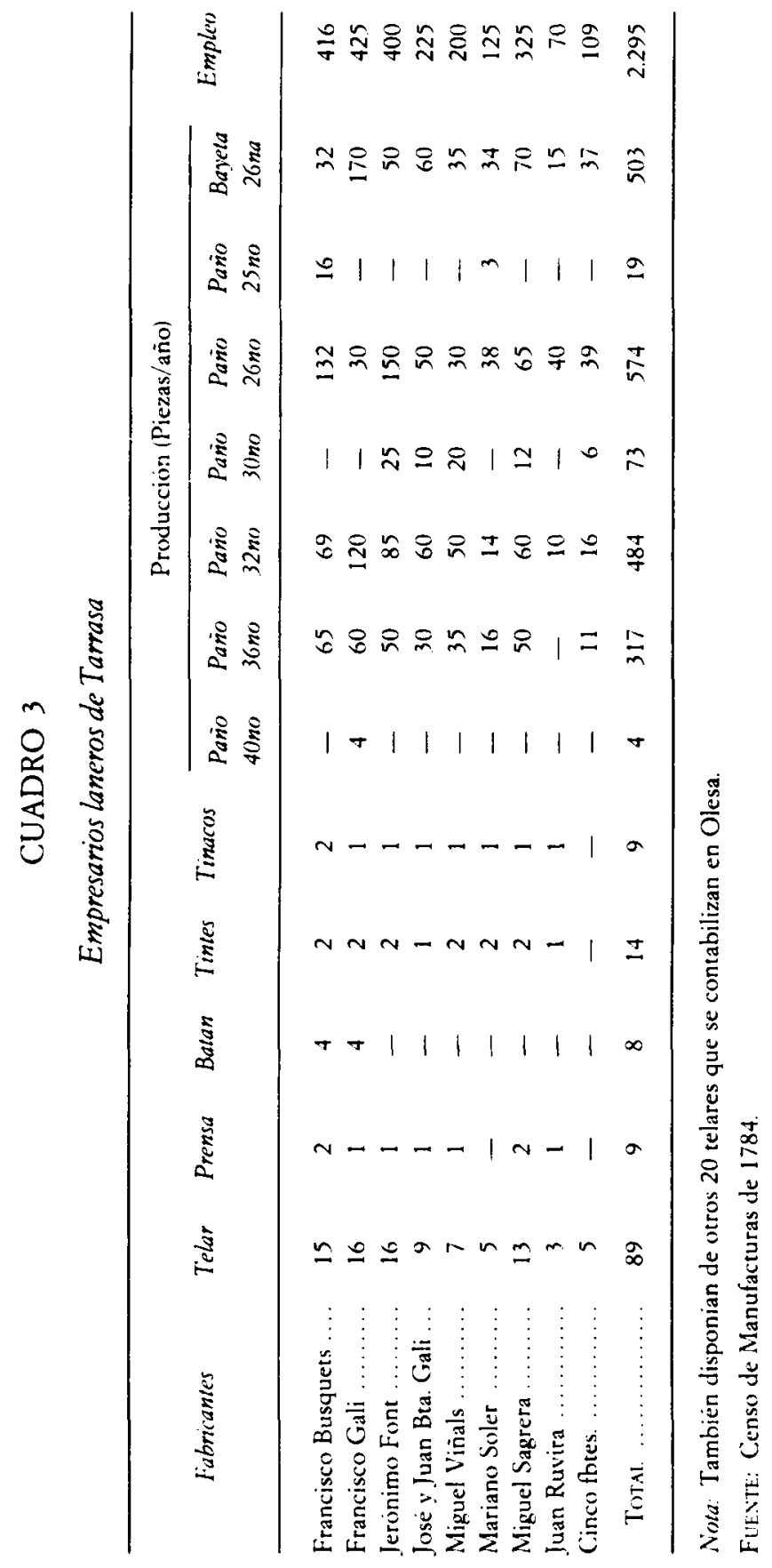




\section{CUADRO 4}

Fabricantes laneros en San Quirce de Basora

\begin{tabular}{|c|c|c|c|}
\hline \multirow{2}{*}{ Empresario } & \multicolumn{3}{|c|}{ Producción (Piezas/año) } \\
\hline & Cordellates & Estameñas & Ratinas \\
\hline José Viñas .......... & 200 & 100 & 4 \\
\hline Juan Guinestet .......... & 12 & 5 & - \\
\hline Bernardo Ruisiñol ...... & 15 & 10 & 4 \\
\hline Juan Rierola ...... & 20 & 4 & - \\
\hline Quirce Espadalet . & 15 & 6 & 5 \\
\hline 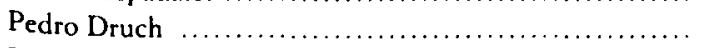 & 10 & 4 & - \\
\hline Juan Castan ................... & 100 & 100 & - \\
\hline 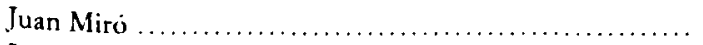 & 25 & 10 & - \\
\hline 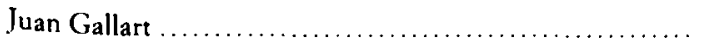 & 10 & 2 & - \\
\hline
\end{tabular}

Fitente: Censo de Manufacturas de 1784.

De igual modo, en el arte de la seda la actividad corporativa convivía con nuevas iniciativas radicadas en la fabricación de medias ${ }^{26}$, quehacer estimulado por el ritmo de las innovaciones técnicas de los telares utilizados y que permitía apreciar el dinamismo empresarial, sobre todo en Mataró (Cuadro 5). Alli, junto al pujante Antonio Ros, otros diversificaban el riesgo introducién. dose en el mundo del algodón, como Simón Melé, que tejía también medias de esta fibra, o Salvador Serralta, que obtenia, simultáneamente, estopillas y que era, además, comerciante en la ciudad. Asimismo, los empresarios preocupados por elevar la calidad de la producción tuvieron uno de sus exponentes en Jaime Roser, de Tortosa, dedicado a las cintas de seda, y en Magin Vallés, de Manresa, que disponía de 140 telares e «introdujo nuevos artefactos» para mejorar sus cintas de hiladillo, aun cuando la cinteria manresana se elaboraba en pequeñas unidades productivas, generalmente familiares ${ }^{27}$.

En cualquier caso, serán los fabricantes vinculados a la elaboración del algodón quienes consoliden la nueva orientación empresarial de la industria textil catalana, la de la manufactura centralizada en un edificio ${ }^{28}$. Aunque la información de Barcelona sólo cuantifique globalmente las 80 fábricas de in-

\footnotetext{
26 Actividad considerada por Vicens Vives como fórmula de desvinculación gremial.

27 Ferrer Alós (1994), p. 226, nota 3.

28 Sanchez (1989), p. 67; Grau i López (1974), passim.
} 
dianas ${ }^{29}$, permite apreciar los rasgos generales de este tipo de establecimiento a través no sólo del volumen productivo, sino también de la gran atracción de mano de obra, más de 8.000 personas, sin incluir el hilado (Cuadro 6). Se trataba de empresarios que diversificaban su oferta con la dedicación al pintado de pañuelos a la chinesca y sobre todo de lienzos, los cuales suponian el 37,32 por 100 de las piezas trabajadas en las factorias de la ciudad condal ${ }^{30}$. Estas fórmulas de organización capitalista se registraban también en otras entidades como Riera y Cía. o Félix Campllonch y Guarro de Mataró. Éste, cuya fábrica de indianas proporcionaba lienzos pintados en menor proporción que las barcelonesas, se dedicaba también al comercio maritimo y de comisión bajo la razón social «Don Salvador Campllonch, Guarro e Hijo», y estaba relacionado con la Compañia de Hilados de Algodón de Barcelona a través de Salvador ${ }^{31}$, razón, quizá, por la que comenzaria a utilizar algodón de América en su fábrica. El papel de su actividad en la ciudad del Maresme se pondera en el Censo de 1784 indicando que distribuia cada semana 7.000 reales en salarios y empleaba a 200 familias en una localidad de 9.800 habitantes. En esta estela de modernización se incluyen iniciativas empresariales extranjeras como la representada por el francés Juan Peiren y su fábrica de medias de algodón instalada en Seo de Urgel por Reales Cédulas de 30 de abril y 25 de mayo de 1775.

Si bien la introducción de nuevas orientaciones en la gestión de la producción se percibía claramente en la industria textil, también podia atisbarse en otros oficios. Así, en los trabajos de cuero el orden gremial encontró la nota disonante de José Alvareda radicado en Horta, exponente de movilización laboral y productiva a gran escala (Apéndice VI). Junto a el, otras empresas sugieren el cambio, como la compañia formada en Barcelona por Liserto y Pablo Badalia con Francisco Coll para procurar la diversificación de la oferta comercializable introduciendo antes, tafiletes y gamuzas de varios colores. También en Mataró algunos fabricantes del curtido se identificaban más allá del gremio con empresas cuya razón social atendía, entre otras, por Cia. de José y Antonio Vilardevo, Cía. de Tomás Fabres, Cia. de Pedro Blanco y Saturnino Masanes, mientras en Olot, de las 19 fábricas de curtidos, se ensalzaba la actividad de los regentadores más acomodados como Francisco Sala, Mateo Serra, José Es-

29 Datos que coinciden con los aportados, desde otra fuente, por Sánchez (1987, p. 262, nota 37, y 1989, p. 82). Se diferencian las fábricas de indianas barcelonesas segun se ajusten o no a las Reales Ordenanzas de 1767 que fijaban un minimo de doce telares por fabrica. Thomson (1994), pp. 227.238 y 261.273 .

30 Sobre esta cuestión y la polémica suscitada, Sánchez (1992, p. 224) indica que la proporción se situaria «en torno al 30 por 100 en el último tercio del siglo xvill».

"Sánchez (1987), p. 266. 
cubos, Jerónimo Masmitja y Lorenzo Pujol. De igual modo, aunque la organización corporativa se dejaba traslucir en la fabricación de jarcia, cordelería y manufactura de esparto, sin embargo, en Mataró se aludia a la individualidad de los 17 «fabricantes» de jarcia, algunos de los cuales se aplicaban a la ob. tención de lona como Ignacio Janer y Jaime Carbonell, y expresaban el efec. to reestructurador que el desarrollo de la construcción naval había tenido sobre actividades con ella relacionadas ${ }^{32}$. Nuevas concepciones empresariales que se mostraban en la fabricación de papel, subsector de «fabricantes con fábrica» que recibe interferencias desde el comercio, cual es el caso de Fran. cisco Capelá, comerciante barcelonés y regentador de uno de los molinos de Sabadell. De forma similar acaece con la elaboración de jabón, ya que la fábrica de Tarragona estaba promovida por el tendero Juan Tomás y las de Mataró por los comerciantes de la ciudad y no faltaban quienes compartian varias manufacturas como Diego Martinez, en Tortosa, fabricante de jabón y de aguardiente.

\section{CUADRO 5}

Fabricantes de medias de seda

\begin{tabular}{llccc}
\hline Localidad & \multicolumn{1}{c}{ Empresario } & Telares & $\begin{array}{c}\text { Producción } \\
\text { (Unidades/año) }\end{array}$ & $\begin{array}{c}\text { Consumo seda } \\
\text { (arrobas/año) }\end{array}$ \\
\hline Mataró & Simón Melé & 6 & 4.800 & 15 \\
Mataró & Antonio Ros & 9 & 6.480 & 27 \\
Mataró & Pedro Conill & 2 & 1.440 & 6 \\
Mataró & Jaime Genis & 2 & 1.440 & 6 \\
Mataró & Pelegrin Comas & 2 & 1.440 & 6 \\
Mataró & José M. Font & 3 & 2.160 & 9 \\
Mataró & Magin Ros & 1 & 720 & 3 \\
Mataró & José Vilardevo & 1 & 720 & 12 \\
Mataró & Tomás Sanz & 4 & 2.880 & 18 \\
Mataró & Rafael Serralta & 6 & 4.320 & - \\
Calella & Francisco Martorell & $*$ & 3.200 & - \\
Vic & Antonio Malats & $*$ & 1.200 & 3 \\
\hline
\end{tabular}

FlifNTE: Censo de Manufacturas de 1784.

32 Los fabricantes de jarcia de Mataró eran: Juan Bautista Albañal, José Galangau, José Puig, Jaime Carbonell, José Amat, Juan Puig. Jose Otset, José Janer, Miguel Mons, Melchor Torras, Antonio Puig, Jose Viñas, Salvador Alsina, Mauricio Carbonell, Ignacio Janer, Gabriel Puig, Pablo Puig. 


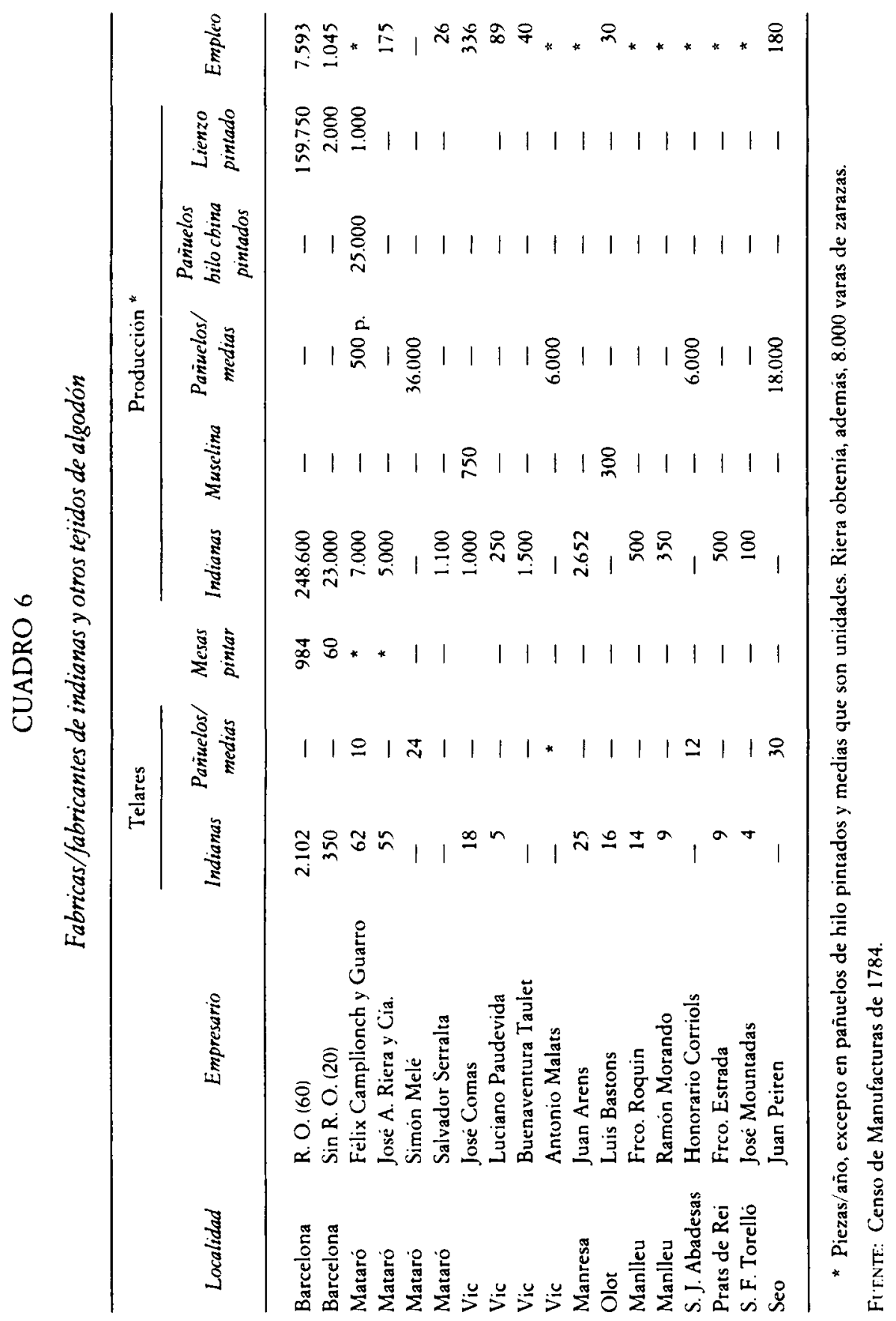


Desde la casa y el obrador la movilización de recursos productivos a mayor escala fue decantando la iniciativa de ciertos hombres y alguna mujer, ya fueran fabricantes que conciliaban varias actividades, comercializaran sus productos, como los fabricantes de paños de Sabadell, o no, ya fueran comerciantes que se introducian en la fabricación, todos ellos protagonizaron la modificación de los presupuestos de las unidades de producción de la industria catalana introduciendo fisuras en el orden gremial y evolucionando hacia la concentración en el proceso productivo. Individualidades que tenian progresivamente más importancia en la obtención del producto final como se exponia en una localidad pequeña como Manlleu ( $1.145 \mathrm{hb}$.), donde dos fabricantes con 23 telares procuraban 850 piezas de tejidos de algodon y 28 telares dispersos aportaban 600 piezas, tal cual sucedia en Tarrasa con los fabricantes de lana o con los de indianas en Barcelona y Mataró e incluso con los de lienzo de Vic.

\subsection{Sistemas de trabajo: Del tiempo parcial a la dedicación exclusiva especializada}

En la década de los ochenta del siglo xvill, en Cataluña, el trabajo industrial guiado por las reglamentaciones gremiales coexistia, y a veces chocaba, con el recurso al trabajo libre que, localizado sobre todo en el ámbito rural, procedia de manos dedicadas a la agricultura que se empleaban a tiempo parcial en este otro cometido y que fueron cambiando paulatinamente su posición en el proceso productivo. En este sentido, quizá sea en la industria textil en la que mejor se aprecie este proceso, aunque también se observa en la transformación del papel ${ }^{33}$ y en el curtido ${ }^{34}$. Junto a la obtención de un bien apto ya para el consumo doméstico, generalmente ordinario, se encontraba la realidad de la segmentación de las tareas que concurrian en la fabricación de los diferentes articulos. Este hecho contribuyó a trabar vinculos entre quienes proporcionaban los semielaborados y los que acababan el producto o dirigian la producción. El Censo de 1784 recoge varios ejemplos de estos sistemas laborales.

Asi, las mujeres de Santa María de Palau Tordera y San Feliu de Codinas hilaban algodón para las fábricas de indianas de Barcelona, Mataró y Calella, las de Esparraguera para las de Capellades. Incluso se movilizaban pueblos

\footnotetext{
33 Gutierrez i Poch (1993), p. i54, y (1994), p. 343.

is Torras i Ribe (1994), p. 301
} 
enteros, como sucedia en Cardedeu y Arbucies, donde se ocupaba a más de 200 mujeres y niños, o en Villamayor, en pro de la fábrica de indianas de Camplionch, de Mataró. Igualmente, en Amer se hilaba para la fäbrica de cotonías de Sarriá del Ter y los tornos de hilar algodón de Rupit se orientaban a abastecer a los fabricantes de Olot, al igual que los 150 tornos repartidos por Seo de Urgell y alrededores aportaban los dos tercios del consumo de la fábrica de medias de Peiren. El sistema laboral expuesto en torno al algodón, ya se practicaba en la lana y la seda. Mientras la hilanza de lana ocupaba, en San Baudilio de Lluçanès, a las féminas de la villa y de los pueblos inmediatos, las mujeres y niños de la parroquia de San Pedro hilaban lana para abastecer a Sabadell y Tarrasa, aunque a esta última también se vinculaban las de Olesa, no en vano, la quinta parte de las personas empleadas por los empresarios tarrasenses del sector lo eran de fuera de la localidad, «por no haber en ella más gente». Simultáneamente, se asistía a la fórmula proporcionada por la empresa de Vicente Plá, en Agramunt, donde, además de lino, se hilaba algodón para la fábrica de indianas de Félix y Francisco Magarola de Barcelona ${ }^{35}$. No sólo el hilado, también el tejido podía integrarse en un proceso de subcontratación, de forma que los tejidos de algodón elaborados en los cuatro telares de Jerónimo Isart, en Villamayor, abastecian a las fábricas de pintados de Mataró y el tejedor de telas de algodón para indianas de Cardedeu las vendía a las de Barcelona. El requerimiento de la mano de obra a tiempo parcial, aprovechando ciertas habilidades tradicionales, también se realiza desde la esfera de la comercialización, como sucedia con las mujeres y niñas de más de cuatro años de Mataró, que recibian hilo y seda de los comerciantes, quienes les pagaban el tanto por vara a que se ajustaban las calidades del encaje o blonda que realizaban. Sistema que dejaba por jornales, diariamente, 5.378 reales de vellón «para las familias pobres de la ciudad». Una modalidad que también practicaban las mujeres de Martorell y las de San Andrés de la Barca que hacian encaje para los comerciantes barceloneses.

La paulatina especialización que se habia iniciado entre la mano de obra dispersa en la hilatura, e incluso en ciertos tejidos, se sanciona en las unidades fábrica que asumen las fases finales del proceso de elaboración. Si en la subdelegación de Berga las distintas cardadoras e hilanderas entregaban la lana preparada a quienes lo tejian y las devanadoras de seda se polarizaban en Cardona, las fábricas de medias de seda y velos de Barcelona constituian una muestra

35 A estos empresarios el propio Pla les proporcionaba 100 quintales de rubia al año de la que «se criaba en Urgell». 
de la división del trabajo especializado entre sus empleados ${ }^{36}$, la cual alcanzaba su ápice en las de tejidos de algodón y pintados ${ }^{37}$. Una composición laboral en la que junto a las mujeres era frecuente la presencia de los niños que llegaron a constituir la cuarta parte del empleo en las fábricas de indianas de la ciudad condal ${ }^{38}$.

En consecuencia, aunque algunos sistemas de trabajo pudieran evocar el modelo protoindustrial ${ }^{39}$, éste no constituye la fórmula única y nitida en Cataluña, ya que en medio de una realidad muy heterogénea, se asiste a la paulatina desvinculación de los planteamientos tradicionales (complementariedad de oficios, mano de obra familiar, rigidez gremial) para responder a las necesidades de producción masiva introduciendo, aparentemente, la racionalidad, la división del trabajo, la especialización en pro de la mejora de la productividad y de la rentabilidad.

\subsection{Equipamiento y técnicas: Dotación/Aprovechamiento/Innovaciones}

Las referencias del Censo de 1784 a las circunstancias técnicas en que se desarrollaba la actividad manufacturera catalana hacen hincapié en los artefactos e instalaciones relacionadas con la industria textil (Apéndice XIII). En este sentido, el afán por mejorar las condiciones de producción y del producto tenía en el hilado del algodón uno de los retos principales, puesto que una gran parte de la materia prima se importaba ya hilada a causa de la escasa confianza que despertaba la calidad de lo hilado en el país, preferible para piezas ordinarias como expresaban el fabricante de estupillas Salvador Serralta o el de muselinas de Olot, a pesar de las diversas menciones sobre el progreso de su hilatura, especialmente en las localidades del Maresme. En el ámbito del Principado se contabilizaban 469 tornos para hilar esta fibra ${ }^{\text {t)}}$, pero se preci-

${ }^{36}$ Las de medias de seda precisaban de 900 hombres para sus telares auxiliados por $200 \mathrm{mu}$ chachos, de 500 mujeres para ovillar, de otras 600 para bordar las medias y de 300 más para co. serias. Las de velos destinaban a 770 hombres para tejer, 3.080 mujeres para ovillar, preparar la seda y coser mantillas y mosquiteras y 80 hombres para pintar fajas, pañuelos y otros.

${ }^{37}$ Thomson (1994), pp. 214-215. A menor escala que algunas barcelonesas pero con similar criterio, la de indianas de Riera, en Mataró, ocupaba a 55 tejedores, 14 pintadores, 31 mucha. chos y 47 mujeres para diferentes tareas.

38. Los trabajadores en las fabricas de indianas de Barcelona eran 4.607 hombres, 1.740 muje res y 2.291 niños.

19 Muset (1989), p. 47, y Torras (1984), passim.

410 Miguel (1995), p. 78 . En el mismo momento se censaban 300 en Jerez de la Frontera bajo la dirección de Felipe Tames. 
saba eficiencia. Por ello, tenía interés el experimento de Pablo Gallifa, tintorero de Mataró. Éste habia inventado un torno para hilar en el que podian trabajar continuamente 60 personas, con la ventaja de que, al mismo tiempo, se hilaba, se formaba ovillo, se torcia, si se deseaba, y quedaba el hilo madejado. Se habia probado con uno que tenía el inventor, «sin la perfección que refería, por no alcanzar sus caudales al coste de 500 pesos fuertes en que está valoradom y, no obstante su imperfección, una hilandera hiló, torció y madejó 36 onzas de lana en un día y 10 onzas de algodón en otro, en un trabajo para el que servian hombres, mujeres, niños y «hasta los mismos ciegos». Aunque no sea el mejor criterio de eficiencia, el valor de su hallazgo puede contrastarse si se consideran las 2,5 onzas de algodón/torno/dia obtenidas en la fábrica de Plá, en Agramunt "1, o la aportación de los 42 tornos que Manuel Campa, factor de la Compañia de Hilados de Barcelona ${ }^{42}$, tenía a su cargo en Tarragona, cada uno de los cuales hilaba 4 onzas de algodón al dia. En esa misma senda de esfuerzo por mejorar la calidad y los rendimientos se sitúa la actuación de Severo Vila, racionero de la catedral de Tarragona, quien, junto a Francisco Villa, gestionaba la actividad de otros 20 tornos para algodón y se preocupaba de pedir modelos e instrumentos a la Real Sociedad Matritense, a Londres y a la fábrica establecida en Seo de Urgel por el francés Peiren, como clara expresión de la importancia de la transferencia tecnológica.

Igualmente el estadio de difusión de nuevos ingenios se puede apreciar en los tornos de hilar seda, de los que se anotaban $152^{43}$, todavia mayoritariamente a la española y asi lo puntualizaban en casi todos los pueblos de las riberas del Segre y del Noguera del corregimiento de Lérida, aunque también se encontraban algunos a la piamontesa en Villafranca, San Feliu de Llobregat, San Juan Despi y Quadra de Palou, asi como a la Vaucanson en Lérida, Oliana, Reus y Esparraguera y únicamente se senalaban tornos para torcer seda en Manresa y Reus. El grado de aprovechamiento de estos dispositivos de hilatura oscilaba entre el apice de las 600 libras de seda/torno/año en Tortosa y la media de 50 de los demás ${ }^{+4}$, amplitud que se corroboraba en el torcido.

t1 Vicente Plá declaraba que en sus 100 tornos se hilaban dos quintales de algodón de América en 10 dias.

t2 Sanchez (1987), pp. 260-261, alude a los esfuerzos de la Compañia de Hilados por mejorar esta operación. Delgado (1990), passim.

t3 En Andalucia se censaban 778 y en Aragón 737.

th El aprovechamiento de algunos tornos de seda catalanes puede apreciarse a continuacion, 
En cuanto a la dotación de telares se aprecian realidades distintas. Mientras la cuantía de los de algodón tenian el protagonismo español y los de seda resultaban todavia relevantes con un grado de especialización del que son buena muestra los 765 de la veleria barcelonesa (Cuadro 7), los de lino aparecian escasamente significativos y los de lana no destacaban como en el pasado, aun cuando faltara el registro de localidades como Centelles o San Llorenç de Morunys ${ }^{45}$. Precisamente, en relación con estos últimos, los datos del Censo de 1784 corroboran, en general, la «tendencia» que deja traslucir la comparación de los datos de 1760/61, 1764/65, del Censo de Artalejo de 1780 y de la información de los Diarios de viajes de Francisco Zamora de 1787/88, aunque con algunos casos discrepantes ${ }^{46}$. Por lo que concierne al nivel de utilización, medido por producción/telar/año o, de forma menos precisa, por la cantidad de fibra trabajada, destacan las 600 arrobas de lana/tejedor de Puigcerdá o las

asi como su significado en contraste con los datos de Cordoba donde se hilaban 1.470 libras de seda/torno/año, 820 en Jaén y 580 en Antequera:

\begin{tabular}{|c|c|c|c|c|}
\hline Localidad & Torno bilar & $\begin{array}{l}\text { Seda bilada } \\
\text { (libras/año) }\end{array}$ & Torno torcer & $\begin{array}{l}\text { Seda lorcida } \\
\text { (libras/año) }\end{array}$ \\
\hline La Bisbal.. & 14 & 300 & - & - \\
\hline 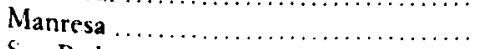 & 24 & 4.800 & 24 & 4.800 \\
\hline San Pedro Riudevitlles $\ldots \ldots \ldots \ldots \ldots \ldots$ & 6 & 300 & - & - \\
\hline Mataró $\ldots \ldots \ldots \ldots \ldots \ldots \ldots \ldots \ldots$ & 1 & 50 & - & - \\
\hline & 1 & 50 & - & - \\
\hline 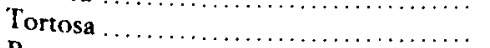 & 5 & 3.000 & - & - \\
\hline 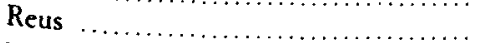 & 16 & 800 & 26 & 65.000 \\
\hline
\end{tabular}

Fuente: Elaboración a partir del Censo de Manufacturas de 1784.

1s Benaul (1991), p. 39, indica la existencia en Cataluña de 2.088 telares de lana, en 1760. Comparando con otras areas españolas, incluidas en el Censo de 1784, sólo en tierras de Segovia habia 656 telares de lana, de ellos 334 en la capital, y 222 en uso en Palencia ciudad. Desde una perspectiva regional, la comparación del numero de telares con otros espacios era:

\begin{tabular}{|c|c|c|c|c|}
\hline & Fibra & Cataluña & Aragón & Andalucia \\
\hline Lino. & & 682 & 1.235 & 5.548 \\
\hline Lana & & 1.146 & 1.475 & 1.380 \\
\hline Seda .... & & 3.927 & 423 & 8.985 \\
\hline Algodón & & 3.767 & - & 一 \\
\hline
\end{tabular}

Fuenre: Censo de Manufacturas de 1784.

th Tras analizar las distintas series los casos claramente discrepantes en el Censo son, al alza, San Baudilio de Lluçanès; a la baja, San Hipólito de Volırega, y, en menor medida, Capellades. (Agradezco a J. M. Benaul las facilidades para comparar estas fuentes.) 
375 arrobas/telar de Capellades ${ }^{4 i}$, en tanto que la eficiencia se expresaba entre los galoneros de Barcelona al mencionar que 50 de los 450 telares regulares disponibles podian fabricar 20 cintas al mismo tiempo de distintas calidades, de forma similar a lo declarado por Jaime Roser en Tortosa, cuyo telar permitia dieciocho ${ }^{48}$. Simultáneamente, los telares de medias de seda obtenían unas 440 medias/telar/año en Reus, llegando a 733 en Mataró ${ }^{49}$. Entre tanto, los telares utilizados en tejidos de lino proporcionaban rendimientos oscilantes, incluso entre localidades de especialización textil (548,5 canas de tejido/ telar/año en Reus frente a las 1.508,5 de la fábrica de lona de Jaime Carbonell en Mataró), de igual manera los dedicados a tejidos de algodón ofrecian desde las casi 112 piezas/telar/año de las fábricas de indianas de Barcelona o las poco más de 100 de Mataró y Manresa, a las 38 de Igualada o las 47 de Berga, con una ocupación de mano de obra muy variada, mientras los de medias de esta fibra, en San Feliu de Guixols, elaboraban 3 pares/telar/dia.

Por lo que concierne a los batanes, todos ellos, los 99, eran de agua, puesto que no se menciona ninguno de caballerias en todo el territorio del Principado (Apéndice XIII). Destaca su ausencia en la ciudad condal y en todos los pueblos de su subdelegación, en tanto que los empresarios laneros de Tarrasa regentaban los de la parroquia de San Pedro y el de Castellar, usado también este último por el fabricante de San Lorenzo Savall ${ }^{50}$. Su nivel de aprovecha-

47 Las productividades en algunas localidades se presentan en el cuadro inmediato, que es posible compararlas, en el caso de los telares, con las 300 arrobas de lana/telar/año tejidas en Bujalance, 100 en Fernán Núnez y 81 en Ronda.

\begin{tabular}{lccccc}
\hline Localidad & $\begin{array}{c}\text { Lana } \\
\text { (arrobas/año) }\end{array}$ & Tejedores & Telares & $\begin{array}{c}\text { Arrobas } \\
\text { Tej-Telar/año }\end{array}$ \\
\hline Puigcerda $\ldots \ldots \ldots \ldots \ldots \ldots \ldots \ldots \ldots \ldots \ldots$ & 1.200 & 2 & - & 600 \\
San Hilari de Sacalm $\ldots \ldots \ldots \ldots \ldots \ldots \ldots$ & 40 & 2 & - & 20 \\
Montella y Martinet $\ldots \ldots \ldots \ldots \ldots \ldots \ldots \ldots$ & 120 & - & 10 & 12 \\
Santa Maria Seva $\ldots \ldots \ldots \ldots \ldots \ldots \ldots \ldots \ldots$ & 12 & 1 & - & 12 \\
Santa Maria Corco $\ldots \ldots \ldots \ldots \ldots \ldots \ldots \ldots$ & 78 & 3 & - & 26 \\
San Juan de Vilatorta $\ldots \ldots \ldots \ldots \ldots \ldots \ldots$ & 48 & 2 & - & 24 \\
Capellades $\ldots \ldots \ldots \ldots \ldots \ldots \ldots \ldots \ldots \ldots \ldots$ & 6.000 & - & 16 & 375 \\
Reus $\ldots \ldots \ldots \ldots \ldots \ldots \ldots \ldots \ldots \ldots \ldots$ & 400 & - & 5 & 80 \\
\hline
\end{tabular}

FUente: Elaboración a partir del Censo de Manufacturas de 1784.

48 Referencias al respecto en Molas (1970), p. 431, y sobre Manresa, Ferrer i Alós (1994), pp. 244.245 .

49 En esta misma fecha en Córdoba se obtenian 356 medias/telar/año y 1392 en el Puerto de Santa Maria.

50 De los batanes de la parroquia de San Pedro uno era propiedad de Francisco Gali de Ta. rrasa y se localizaba exactamente en San Julian de Altura, los otros dos estaban en San Vicente de Junqueras y eran de Antonio Font, de Sabadell, y de Juan Amat. 
miento puede percibirse en el de Vigas que beneficiaba 40 piezas al año, el de Santa María de Palau Tordera 24, o en cada uno de los de Puigtiños con sólo unas 7 piezas, cantidades expresivas de su localización en zonas de densidad lanera claramente distinta. Entre los batanes habia algunos especificos para pieles como los de San Pedro de Roda en beneficio de los curtidores de Vic y el de San Sadurni o los de Lérida. Si en la ciudad de Barcelona no se censaban batanes, si numerosas prensas, 25 de las 68 existentes en el Principado, lo que representaba la mayor concentración de este tipo de artefacto para ropas de lana, seda y medias, mientras se registraba una en Seo de Urgel y otra en Tortosa especificamente para tejidos de seda y estambre. Estas prensas eran de madera, aunque algunas se completaban con planchas de hierro que oscilaban en su peso desde las 50 arrobas de las existentes en Manresa a las 5 arrobas de Tarrasa.

\section{CUADRO 7}

Equipamiento de la velería barcelonesa

\begin{tabular}{|c|c|c|c|}
\hline Tipo de telar & Cantidad & Tipo de telar & Cantidad \\
\hline Sargas con flores y sin ellas ........... & 84 & Pañuelos de gasa & 28 \\
\hline Pañuelos de seda $\ldots \ldots \ldots \ldots \ldots \ldots \ldots$ & 234 & Gasas ordinarias ................ & 115 \\
\hline Tafetanes para vestidos $y$ forros ........ & 87 & Gasa de seda con mezcla de hilo & 4 \\
\hline Fajas $\ldots \ldots \ldots \ldots \ldots \ldots \ldots \ldots \ldots$ & 28 & Gasas de mosquiteras $\ldots \ldots \ldots \ldots \ldots$ & 58 \\
\hline Pompolinas ...... & 18 & Gasas de seda y latas $\ldots \ldots \ldots \ldots \ldots \ldots$ & 8 \\
\hline Tocas de la Reina $\ldots \ldots \ldots \ldots \ldots \ldots \ldots$ & 13 & Gasa de nueva invención afantasia».. & 1 \\
\hline Tafetanes de lustre $\ldots \ldots \ldots \ldots \ldots \ldots$ & 36 & Merlines finos y regulares...$\ldots \ldots \ldots$ & 15 \\
\hline Espumilla ........... & 15 & Boratas de seda y estambre .......... & 7 \\
\hline Gasa de mantillas . . . . . . . . . . . . . . . & 8 & Muselinas finas $\ldots \ldots \ldots \ldots$ & 6 \\
\hline
\end{tabular}

FueNTE: Censo de Manufacturas de 1784.

El acabado de las telas precisaba de un equipamiento tintorero que podia encontrarse en los 105 tintes, de los que 33 eran para seda. Los de lana se concentraban en Barcelona, Tarrasa, Manresa y Olot, en tanto que los de seda radicaban en Reus, Manresa y Mataró. Los métodos de tinción no parece que hubieran progresado mucho, a decir de los interesados, aunque resulta explicito que para los azules y verdes no se usara pastel ni orchilla sino añil, granza y 
miel en Mataró ${ }^{51}$. Operaban mediante estampado y el baño de tina, donde empleaban cochinilla, palo brasil y campeche como declaraban también en Valls y Puigcerdá. En Manresa, se daban todos los colores menos rosa y rojo y en Olesa se prefería el negro y se mezclaban «el pie de granza con tártaro de Cuba y vitriolom. Las referencias a otras técnicas de tratamiento de tejidos se centran en el blanqueo de los lienzos e indianas. En el primer caso la fábrica de María y Baltasar Viza, de Mataró, lo realizaba con calidad «como en el extranjero". Para esa misma finalidad estaba disponiendo José Arimón, en Horta, otro establecimiento dedicado a blanquear hilo de lino y cáñamo para medias. Entre tanto, progresaban los cuatro prados de blanqueo de indianas de Hospitalet y los de San Andrés del Besós asi como los entre 20 a 30 de San Martín de Provençals que trabajaban más de 2.000 piezas al año por prado con la ayuda de 10 a 15 hombres.

El caracter nuclear de las actividades textiles empaña las alusiones de equipamiento o las pinceladas técnicas de otras actividades. Resulta llamativa la ausencia de mención a la infraestructura de las tenerias respecto a noques o tahonas, entre otros, situación equivalente en otras manufacturas, ya que sólo podemos saber que las calderas de jabón piedra de Salvador Issart tenian una cavida de 130 y 160 quintales, al parecer superior a las diseñadas un siglo más tarde en una zona jabonera destacada como Mallorca 52 o que el molino de papel de Martorell tenia cuatro tinas. Datos escuetos que contrastan con la profusión respecto al mundo textil.

\subsection{Materias primas: Abastecimiento y consumos}

Las unidades de producción manufacturera disponian de varios de los inputs necesarios in situ, aunque a veces fueran insuficientes, a excepción del algodón que provenía totalmente del exterior. En este sentido, la preferencia por el algodón de Malta, ya hilado, se detecta en los establecimientos de Félix Campllonch y Guarro o en el de Riera de Mataró, en San Feliu de Guixols o Manresa y en las fábrica de indianas y muselinas de Olot, hasta el punto de

"Los tintoreros de Mataró eran Ignacio Jonulla, Jose Grou, Manuel Sanz, Pablo Tio, Serapio Chivilles, Pablo Gallifa. Utilizaban para la seda negro, encarnado, carmesi, morados finos, verdes y diferentes azules, color fuego, canela, orujo, café plomado, rosa seca, viola y amarillo. En los lienzos de hilo: azul oscuro plomado, canela, encarnados, verdes y amarillos. Los colores de estambre eran negro, azul, amarillo, verde, plomo y orujo oscuro. En estos últimos tejidos usaban pocas veces pastel, lo suplian con lejia y palomina.

"2 Ramón (1994), p. 35, nota 34. 
que representaba las dos terceras partes del total consumido en estas instalaciones. Entretanto, el utilizado en Berga y en la fábrica de Francisco Estrada en Prats de Rei, se importaba sin hilar, mientras los fabricantes de gorros y medias de Olot empleaban el hilado en la zona y un poco de Francia. En contraste, el recurso al algodón americano predominaba en el ámbito tarraconense y enclaves como Capellades e Igualada. La tendencia hacia el indiano, impulsada desde la Compañia de Hilados de Barcelona ${ }^{53}$, lo expresaria la fábrica de medias de Simón Melé, en Mataró, que utilizaba algodón de América en 15 telares y de Malta en 9. La cuantia de los consumos se des. prende de lo manifestado para las 80 fábricas de indianas de Barcelona, 92.690 arrobas de algodón (2.317.250 libras) ${ }^{54}$, mientras las fábricas de Campllonch y Riera declaraban utilizar 700.000 libras de algodón hilado de Malta cada una, cifra que parece excesiva. En cuanto a la lana, aunque el Censo de 1784 es poco explícito al respecto, se alude al abastecimiento procedente de Aragón, en relación con el que algunas noticias detectan entre $1778 \mathrm{y}$ 1783 un descenso del 35 por 100 en la cantidad de lana fina/entrefina y 18 por 100 en la lana basta registrada en la Administración de Fraga para las fábricas del Principado 55 , en una trayectoria de creciente abastecimiento exterior de la misma. Por otra parte, ya consta que, desde las últimas décadas del siglo XVIII, la lana castellana, segoviana y soriana, era demandada por los fabricantes de Barcelona, Sabadell y Tarrasa, redistribuida habitualmente desde Zaragoza ${ }^{56}$.

Pero también se superaban los limites del Principado en el acopio de lino cuando se iniciaba la producción a escala y de calidad tal como manifestaban Vicente Pla que consumia 100 quintales de lino de Holanda, frente a 50 del pais y otros 50 de cáñamo, o Maria y Baltasar Viza, de Mataró, que empleaban cáñamo de Bolonia y lino de Holanda por ser más fino, al igual que para los encajes, mientras el pintado de lienzos se hacia sobre variedades extranjeras como laval, constanzas, platillas o lienzos de Suiza, tal cual se indicaba desde la fábrica de Campllonch y Guarro, de Mataró. Asimismo, se acudía a la seda de Valencia, para las blondas, $y$ de Aragón, de donde procedian igualmente tra.

s) Sanchez (1987), p. 265.

st $\mathrm{Si}$ se considera arroba catalana (26 libras 12 onzas/arroba) serian, aproximadamente, 2.409.940 libras. Supondria un consumo superior al sugerido por Maixé (1988), p. 367.

" AGS, DGR, II Remesa, leg. 4925. En 1778 se contabilizaron 82.677 arrobas y 27 libras de lana fina/entrefina y 1.268 arrobas y 24 libras de lana basta, mientras que en 1783 fueron 54.023 arrobas y 1.045 arrobas y 17 libras, respectivamente. La introducción por esta via incrementa ligeramente, en 1778, la cantidad ofrecida para 1760 por Benaul (1991), p. 410 , pero desciende nota. blemente en 1783 .

s, Garcia Sanz (1994), p. 200, además de otros datos que, amablemente, me ha facilitado. 
po para papel y pieles para curtidos ${ }^{57}$, aunque ciertos curtientes fueran del lugar, como comunicaban desde Olot, cuyos maestros curtidores utilizaban para cordobanes y suela catalana el zumaque de la zona y para la suela inglesa, baqueta, becerrillos y badanas corteza de encina ${ }^{58}$. Asimismo se precisaba más aceite para fabricar jabón que escaseaba incluso en Tortosa, al tiempo que la insuficiencia de materias primas adecuadas se ponia de manifiesto en las actividades metalúrgicas por cuanto las fargas se proveian en el valle de Carol, en Francia, ante la falta de carbón, si bien el mineral de hierro de Aynet, del que se abastecian las de los Castellarnau (Alins, Aynet y Llavorsi), era de buena calidad frente al inferior de Tahull. En cualquier caso, el recurso al exterior del Principado para la adquisición de materias primas configuró redes de comercialización con el resto de la península, América y Europa, las cuales eran también utilizadas para dar salida a la producción.

\subsection{Producción: Diversidad, calidades, destino}

El haz de manufacturas aludidas proporcionaba una oferta, cuyas características se reflejan, en parte, en los Apéndices I-XII. Los tejidos de lino y cañamo eran en general ordinarios y para la cobertura de las necesidades de los «naturales», confirmada por numerosos testimonios en Lérida, en las subdele. gaciones de Manresa y Berga, en Villafranca, Torruella y Foix, en el corregimiento de Salas, en San Andrés de Tona, en La Bisbal o en Alp, donde se especificaba que «el tejido de cáñamo es muy basto". No obstante, la apertura del horizonte comercial incorporaba más calidad y diversidad en los proporcionados por las fábricas ya indicadas de Vic o las de lona de Mataró, en los de Cervera y Guissona, asi como en las medias de aguja tejidas en la de Virgilles, de Villafranca, tratando de emular lo extranjero ${ }^{59}$. A la comercialización exterior se orientaba el encaje negro elaborado por las mujeres de Cornellá o las redes para coger sardinas hechas por las de San Feliu de Guixols que se enviaban a toda España, junto al hilo de jäbega y las nasas de Cornellá que llegaban hasta las Indias. A la demanda muy precisa del ejército respondia la pro-

"Sobre los intereses comerciales catalanes en las matcrias primas aragonesas, Gómez Zorra. quino (1988), p. 411, Torras (1990), passim.

3* Acerca de los curtientes empleados con más frecuencia en Cataluña, Torras i Ribé (1994), pp. 314.316 .

59 En el establecimiento viqués de Llusia y Cía. se obtenian telas de calidad uparecida a las extranjeras» con una marca de 3,5 a 4,5 palmos, y en el de Carbonell se tejían lonas "lo más a 2 hilos por púa igual que las velas de lancha y lo mismo para las velas de bonetesm. 
ducción de hilo que Vicente Plá enviaba a Barcelona para tejer medias de la tropa y la de las dos fábricas de lienzo de cáñamo de Santa Coloma de Farnés ${ }^{60}$.

La producción de géneros de lana, que parece situarse en torno a las 15.500 piezas, habria descendido apreciablemente respecto a los datos de 1760 y 1765. Incluia una gama en la que predominaban los paños seguidos de la ropa estrecha (cordellates y estameñas) y de las bayetas (Apéndice II) ${ }^{61}$. Los paños superfinos (treintenos y superiores) predominaban en Tarrasa, Sabadell y Barcelona, aunque también abundaban en ellas los finos (26nos y 24nos), asi como estos últimos y los más inferiores hasta el buriel en la subdelegación de Villafranca. Las bayetas (26nas y 18nas), estameñas, cordellates, ratinas destacaban en la subdelegación Vic/Camprodón y en la de Manresa y sólo se contaba con algunos monfores de la fábrica de Francisco Camprodón en Taradell. La profusión de otros artículos de lana como medias, gorros (barretinas de Olot), fajas y culebras de estambre caracterizaba a las subdelegaciones de Puigcerda' Seo de Urgel y de Vic/Camprodón. La comercialización de los tejidos de lana se ampliaba desde el Principado a los mercados del interior peninsular para aquellos distinguidos por su calidad o singularidad ${ }^{62}$.

El arte de la seda proporcionaba, además de medias, velos, cintas o pañuelos, una multiplicidad de artículos cuyo carácter refinado se confirmaba en la declaración productiva del gremio de cordoneros de Barcelona (Cuadro 8), orientados a una demanda de elite nacional y americana.

Las fábricas dedicadas a los tejidos de algodón y su complemento de lienzos pintados, proveian de artículos exclusivos en el ámbito español, si se hace la salvedad de los pintados obtenidos en ese momento en El Puerto de Santa María. Indianas, ordinarias y finas ${ }^{63}$, pañuelos, cotonias, muselinas, además de medias y gorros que, en ocasiones, eran de mezcla con estambre e hilo en

"Estas fabricas proporcionaban tres calidades: Lienzo para camisas de las guardias españolas y valonas y soldados de caballeria (4 palmos de ancho), para la infanteria y forros de calzones de dichos guardias y con mezcla de hilo crudo para mochilas y capotones de rancheros (tres palmos y medio).

6) Como contraste, en el area segoviana se tejian 13.467 piezas y solo en la ciudad 6.505 pie. zas de 37,5 varas cada pieza (la vara equivalente a $0,8356 \mathrm{~m}$.). Convendrá en este contexto indicar, con las diferencias estructurales pertinentes, que los 8 mayores fabricantes de Tarrasa obtenian 1.399 piezas de paño mientras los 8 principales de Segovia tejian 2.342, ciudad donde en 1752, según datos facilitados por García Sanz, los 8 fabricantes más importantes obtenian 1.485 piezas de paño. Respecto a la producción de bayetas, conviene señalar que en Antequera se producian 7.200 piezas en 1784 .

62 Benaul (1991), pp. 432 y ss. Torras (1995), pp. 116-117.

6) Las indianas fabricadas por Campllonch eran de 5, 4,5, 4 y 3 palmos, siendo corrientes las primeras. Cada pieza tenia 12 canas. 
Olot, San Juan de las Abadesas, Puigcerdá o San Feliu de Torelló, se destinaban al consumo del Reino y de Ultramar, como afirmaba Simón Melé, de Mataró, respecto de las medias que elaboraba ${ }^{6+}$. Ambos mercados recibian tam. bién los sombreros de la ciudad del Maresme, en contraste con los «muy ordinarios» de Lérida.

\section{CUADRO 8}

Producción cordonera barcelonesa

\begin{tabular}{|c|c|}
\hline Producto & Cantidad/año \\
\hline 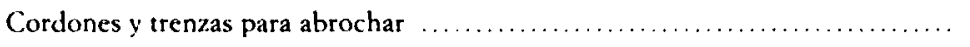 & 50.000 varas \\
\hline $\begin{array}{c}\text { Cordones para espada con horlas de seda o mezcla de oro y plata con brillantes } \\
\text { y talco } \ldots \ldots \ldots \ldots \ldots \ldots \ldots \ldots \ldots \ldots\end{array}$ & 4.000 \\
\hline 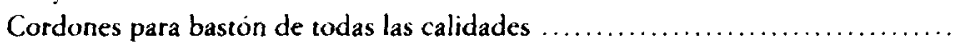 & 20.000 \\
\hline Cordones para relojes...........$\ldots \ldots \ldots$ & 50.000 \\
\hline $\begin{array}{l}\text { Cordones para espejos cornucopias, cuadros } y \text { aranas de seda, estambre } y \\
\quad \text { algodon } \ldots \ldots \ldots \ldots \ldots \ldots \ldots \ldots \ldots \ldots \ldots \ldots \ldots \ldots \ldots \ldots \ldots \ldots \ldots \ldots \ldots \ldots \ldots \ldots \ldots \ldots \ldots \ldots \ldots\end{array}$ & 40.000 \\
\hline Cordones para cortinas y orros adornos de la casa $\ldots \ldots \ldots \ldots \ldots \ldots \ldots \ldots \ldots \ldots \ldots \ldots$ & 50.000 varas \\
\hline 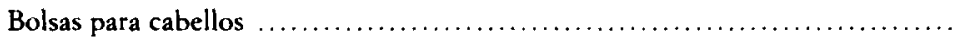 & 250 \\
\hline Bolsillos para dinero solo y con mezcla de oro y plata $\ldots \ldots \ldots \ldots \ldots \ldots \ldots \ldots \ldots \ldots \ldots \ldots$ & 300.000 \\
\hline Botunes de oro y plata para vestidos $\ldots \ldots \ldots \ldots \ldots \ldots$ & 7.200 .000 \\
\hline Botones y presillas para sombreros de seda, oro y plata ... & 50.000 \\
\hline Redecillas para cabello de distintas labores con sus borlas $\ldots \ldots \ldots \ldots \ldots \ldots \ldots$ & 180.000 \\
\hline 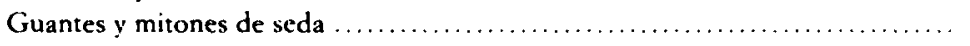 & 2.400 \\
\hline Charreteras de oro y plata para divisas de los oficiales del ejército y marina ..... & 10.000 \\
\hline Charreteras de seda, pelo, estambre con oro y plata para sargentos $\ldots \ldots \ldots \ldots \ldots$ & 6.000 \\
\hline
\end{tabular}

Fufnte: Censo de Manufacturas de 1784.

Los artículos de piel catalanes destacaban por los cordobanes y gamuzas, propiciados por Barcelona, Igualada, Horta y Vic. Menor se presentaba la oferta de suela y baquetas, aunque fuera más común, o la más selecta de becerrillo y pergaminos, si bien esta última era la más amplia de Barcelona. La calidad oscilaba desde la inferior de las badanas de Oliana y menos mala de las suelas, cordobanes y baquetas obtenidas en Palafrugell, que eran para uso «del pais», a la muy buena clase lograda en la suela de Igualada, "compuesta a la inglesa».

(4) Sanchez (1989 b), passim, Thomson (1994), pp. 255-261. 
La gama de papel, salvando las lagunas cuantitativas de La Riba, estaba dominada por el blanco, al que se sumaba algo de florete trabajado en San Esteban de Palau Tordera, seguido del de estraza y algunos cartones. Su proyección al mercado interior, en estrecha relación con la demanda de la Administración, y al mercado americano le procuraron un gran estimulo a pesar de la insuficiencia de materias primas, experimentando un notable crecimiento (Apéndice VII) respecto a las 120.800 resmas obtenidas en $1775^{65}$. Expansión que afectaba también a la producción de cordeleria, jarcia y manufactura de esparto, encaminada al abastecimiento de las necesidades del Principado, donde avanzaba la demanda derivada de la construcción naval. Las localidades costeras, en general, se autoabastecian, pero en Mataró se aprecia la ampliación de la oferta, no en vano, era la única población en la que se aludia a la construcción naval de gran alcance que proporcionaba barcos de hasta 600 toneladas para el comercio con América.

Por lo que se refiere a otras producciones manufactureras, mientras unas como la jabonera se inclinaba hacia la variante dura sobresaliendo la calidad del jabón de Arbeca, aunque con un horizonte limitado de consumo, otras desbordaban los límites catalanes, cual acaecia con los tapones de La Bisbal y Palafrugell que se destinaban a Francia, las cardas fabricadas en Olot que abastecian a toda la provincia y a «mucha parte del Reino de Aragón» o las camas con perfiles dorados y esculturas que desde Olot abastecian al mercado americano. Alli se dirigia igualmente el aguardiente, aunque el de Reus fuera "el principal tráfico de la ciudad con los paises del Norte» ${ }^{66}$, en claro contraste con su producción de loza que sólo abastecía el campo de Tarragona.

Se pone de manifiesto en las respuestas los rasgos de una producción cuya cuantía y calidad permitia abastecer la propia demanda del Principado y competir, en ciertos casos, con ventaja comparativa, en el mercado interior y americano, pero cuya obtención no estaba exenta de desequilibrios y necesitada de ajustes.

\section{CONSIDERACIONES FINALES}

El Administrador de la Aduana de Barcelona indicaba que, entre el momento de la confección de la Relación, en 1784, y el instante en el que expide el documento, junio de 1785, «se han aumentado muchas fábricas, asi en la

65 Delgado (1991), p. 206; Gutiérrez i Poch (1988), pp. 358-360.

th Aspecto corroborado por otras fuentes en Puig (1993), p. 95, y Segarra (1988), passim. 
ciudad como en el resto del Principado...», sin embargo, «al presente se observa alguna suspensión ...”, de lo que responsabiliza a la apertura del comercio con Filipinas. La percepción de relativa expansión era necesario tamizarla. En efecto, el análisis de la información vertida en el Censo de Manufacturas de 1784 , al proporcionar una perspectiva global, permite algunas otras consideraciones, además de las indicadas ya a lo largo de este trabajo. Así, en el marco de la actividad textil, el tejido de lino/cáñamo presenta signos de estancamiento en la producción tradicional junto a algunas iniciativas de modernización, al tiempo que el arte de la seda alerta sobre la recesión. A este respecto, Manresa, de relevante sederia, manifestaba la existencia de 24 fábricas de cintas de seda paradas frente a 57 corrientes, situación que trasladada a los galoneros resultaba que de los 214 telares declarados, 86 estaban sin uso. Estado debido, quizá, a una crisis en el abastecimiento de seda ${ }^{67}$, que no se constataba en Barcelona, aunque sí en Andalucia. Entretanto, la manufactura lanera ofrecia en 1784 un descenso acusado de la producción respecto a la década del sesenta, aun cuando algunas localidades pudieran exagerar sus dificultades en la pugna con el algodón, lo que no es óbice para que se refuercen las posiciones de unos pocos núcleos (Barcelona, Tarrasa, Sabadell e Igualada) dedicados a tejidos de calidad 68. Por el contrario, eran múltiples los testimonios sobre los avances de la hilatura de algodón en Granollers, Ripollet, San Celoni, en el Maresme, asi como el esfuerzo por evitar el estrangulamiento en el abastecimiento de materia prima e incorporar innovaciones tecnológicas ${ }^{69}$.

La reestructuración y los contrastes se aprecian en otros oficios. En este sentido, los curtidos de Lérida estaban en apreciable decadencia y los de Manresa tenían poca consideración, frente a los destacados de Barcelona o Igualada. Los molinos de papel de Sabadell eran de bastante consumo de materias primas, mientras los de Lérida trabajaban a temporadas y aún se construia uno en Pons. La caldera de jabón de Tora hacia dos años que no estaba corriente, al igual que la de Cervera o Tiurana, y en Lérida sólo una trabajaba continuamente, ritmo que compartía la de Solsona, en oposición al dinamismo de $\mathrm{Ma}$ taró que se apreciaba, también, en sus fábricas de jarcia y cordeleria, las cuales podrian labrar más cáñamo «si dispusieran de materia prima». Asimismo, si las

${ }_{67}$ Ferrer i Alos (1986). p. 21. A pesar de la descripción de esplendor de Jaume Caresmar, citado por este mismo autor (p. 14).

${ }_{68}$ En 1784 la estructura porcentual sería: Paños (41), bayetas (20), cordellates/estameñas (39), valores que comparados con $1760(40,7,9,8,49,3)$ y $1804(47,4,10,1,42)$ ofrecidos por Benaul (1991, p. 416) confirman ese proceso, aunque los renglones de comparación no sean estrictamente iguales.

69 Thomson (1994), pp. 281-296. 
fábricas de aguardiente de Salas no prosperaban por «lo costoso del transporte hasta el mar, a causa de la falta de carreteras y buenos caminos» y la de Tortosa estaba parada, se asistía al despliegue de las instalaciones en la subdelegación de Manresa. Simultáneamente, el arte de fabricar anzuelos y «otras cosas de hierro» está en «alguna decadencia» porque «el hierro en hilo viene solamente del extranjero, de Francia y Holanda" y cada quintal vale 30 libras, cuando «en el pasado se pagaba a 18 libras el quintal» 70 .

Ante la percepción de una realidad con problemas se alzan distintas voces que ponen el acento en lo que creen el origen de esos desequilibrios para corregirlos. El corregidor del Talarn indicaba que «si se hicieran los caminos proyectados se formarían varias fábricas y se fomentaria la industria y el comercio», del mismo modo se consideraban necesarias carreteras para facilitar la comunicación de los pueblos del Vallés a fin de agilizar el transporte de madera y cáñamo a la zona de Mataró en provecho de la construcción naval. Por otro lado, si se evitara la entrada de lienzos extranjeros pintados, si se rebajaran los derechos de aduana de pelo de camello, lana de vicuña y castor, si se propiciara la venida de cueros de Buenos Aires y los becerrillos del exterior tuviesen franquicia de derechos «por la escasez que tienen en nuestra Españan, se estimularian los subsectores correspondientes. Además, sería preciso promover el tránsito de aceite gordo, sosas y barrillas, evitando que se transportaran a Marsella, sobre todo desde Mallorca y, así, los aceites buenos, que se consumian muchas veces en el jabón blando, quedarian para abasto. Finalmente, se planteaba la conveniencia de prohibir la salida de corcho en especie o recargar los derechos de extracción, a fin de no encarecer la materia prima de la industria taponera. Demandas que expresaban la orientación a favor de una política mercantilista que fomentara la actividad industrial catalana, aliviando la fiscalidad de las materias primas importadas o dificultando la salida de las que existian, en tanto se precisaran, y protegiendo los mercados a los que su producción se destinaba, todo ello favorecido por la mejora en la fluidez del transporte $i$.

Se adoptaran o no las medidas de política económica solicitadas, la panorámica del sector manufacturero catalán proporcionada por el Censo de 1784, mediante sus referencias cualitativas y su información cuantitativa, facilita las coordenadas de un proceso de cambio, enfatizado en el sector lanero. Se aprecia, en relación con ello, la decantación de los quehaceres y centros industria-

\footnotetext{
7" Habia habido una fäbrica en Sallent y otra en Gerona en las que se llego a perfeccionar el hilo de hierro, de forma que «no habia diferencia con el de Alemania».

is Sanchez (1988), pp. 10-18.
} 
les más relevantes, los cuales iban gravitando hacia la zona litoral con preferencia por el entorno barcelonés, mientras se asistía a la latencia, precariedad e incluso retroceso de las escasas actividades transformadoras de las tierras de Lérida y nordeste de Gerona. Dinámica relacionada con múltiples variables como las condiciones de la actividad agraria, los niveles de renta, la capacidad de demanda, la infraestructura y la disponibilidad de materias primas y capital en cada una de las áreas. Crecimiento con ajustes y concentración espacial de un proceso económico en el que se va imponiendo la transformación y la conquista de mercados ${ }^{2}$. Precisamente, la generación de esa trama de vínculos industriales, y económicos en general, por la capital del Principado era objeto de apologia por el Administrador de la Aduana cuando indicaba: «Es ésta (Barcelona) una ciudad de industria y comercio en donde no falta arte ni oficio que sirva a la necesidad, decencia y lujo y no sólo comprenden sus manufacturas el recinto de su población y el del Principado sino también de toda España y el de las dos Américas en donde tiene comercio floreciente, pues, no contentos sus naturales con el trabajo preciso para ocurrir a las necesidades de estos habitantes, lo extienden a las urgencias de los de fuera de su Provincia con quienes mantienen un comercio lucrativo...».

\section{BIBLIOGRAFIA}

Badosa 1 Coll, E. (1984): «La industria rural a Catalunya a finales del siglo xviII», Actas del Primer Congreso de Historia de Cataluña, vol. 1, pp. 345.349

Benaul., J. M. (1991): La industria textil llanera a Catalunya. 1750-1870. El pròces d'industrializacio al districte industrial de Sabadell-Terrasa, Barcelona.

- (1992): «Los origenes de la empresa textil lanera en Sabadell y Terrasa en el siglo xvilı, Revista de Historia Industrial, núm. 1, pp. 39-61.

(1994): «Especialización y adaptación al mercado de la industria textil lanera (1750-1913)», La cara oculta de la industrialización española, Madrid, pp. 199.213.

Benavente, J., y Nicolau I Nos, R. (1990): «La poblacióm, Història econòmica de Catalunya contemporàia, vol. 2, Enciclopédia catalana, Barcelona, pp. 11-119.

BenEt I Clara, A. (1988): «La industrialitzacio d'un poble de la Catalunya central: Sallent (1750-1808)m, Rev. Pedralbes, VIII, Barcelona, pp. 339-347.

- (1989): «Les fargues d'aram y de filferro al segle xvin», L'activitat industrial a la Catalunya interior, Manresa, pp. 51-65.

DELGado, J. M. (1983): «La fabricació manual de paper a Catalunya», L'Avenç, pp. 726.733.

72 Vilar (1981), pp. 178.179. 
- (1990): «De la filarura manual a la mecànica. Un capitol del desenvolupement de la indùstria cotonera a Catalunya (1749-1814)», Reçerques, 23, pp. 161-179.

-_ (1991): «El paper», Història economica de la Catalunya contemporània. Siglo XIX, vol. 3, Enciclopèdia catalana, Barcelona, pp. 205-232.

Enrich, J.; Pfidra7., X.; Puic; M. (1990): “Cal Granotes. Una adoberia del segle xvill», Museu comarcal de l'Anoia, Igualada.

Ferrer I Alos, Ll. (1986): «Els origens de la industrialització a la Catalunya central», Episodis de la Historia, 132, R. Dalmau Editor, Barcelona.

- (1994): "La cintería en Manresa en el siglo xix. Industrialización y pequeña em. presan, La cara oculta de la industrialización española, Madrid, pp. 225-266.

Garcia SANZ, A. (1994): «El final de la Mesta», Mesta, trasbumancia y vida pastoril, Madrid, pp. 191-206.

Gomel Zorraquino, J. (1988): La burguesia mercantil catalana y su presencia en Aragón (1770-1808), Pedralbes, vol. II, pp. 405-423.

Grael.Ls, E. (1972): La industria dels claus a Ripoll. Contribució a l'estudi de la farga catalana, Barcelona.

- (1990): Els origens industrials de Catalunva. Ripoll bressol de la industrialització, Ed. Maideu, Ripoll.

GraU, R., y LOPEZ, M. (1974): «Empresari i capitalista a la manufactura catalana del segle Xvill. Introducció a l'estudi de les fabriques d'indianes», Reçerques, 4, pp. 19-57.

Gutierrez i POCH, M. (1988): «La manufactura paperera catalana a la segona meitat del segle xvIII: Una introducción, Rev. Pedralbes, VIII, Barcelona, pp. 349-363.

- (1993): «Trabajo y materias primas en la manufactura preindustrial: El papel», Revista de Historia Industrial 4, pp. 147-157.

- (1994): «Tradición y cambio tecnológico: La industria papelera española. 17501936», La cara oculta de la industrialización española, Madrid, pp. 341-365.

LLuCH, E. (1981): «La Revolució industrial a la Garrotxa (1777-1822)», Annales de IInstitut d'Estudis Gironins, vol XXV-II, pp. 193-230.

MAJXE ALteS, J. C. (1988): «El mercado algodonero y la producción industrial en Cataluña, 1780-1790», Rev. Pedralbes, VIII, Barcelona, pp. 365.384.

Maluquer de Motes, J. (1984): «La producción de hierro en la farga catalana», Revista de Historia Económica, II, núm. 3, pp. 83-95.

Miguel., I. (1995): «El sector manufacturero andaluz en el Censo de 1784», Revista de Estudios Regionales (enero-abril), Universidades de Andalucia, Málaga, pp. 65-114.

MoLAS, P. (1970): Los gremios barceloneses del siglo xvill, CECA, Madrid.

Muset, A. (1989): «Protoindustria e industria dispersa en la Cataluña del siglo xvil. La pañeria de Esparreguera y Olesa de Montserrat", Revista de Historia Económica, VII, núm. 1, pp. $45-67$.

NADAL, J. (1991): «La industria cotonera», Historia económica de la Calunya contemporánea. Enciclopedia catalana, Barcelona, pp. 13-85.

Pulg, M. (1993): «La modernización de la industria del alcohol en Tarragona, Ciudad Real, Navarra y Granada», Revista de Historia Industrial, 4, pp. 91-111.

RAMÓN I MuNoz, R. (1994): «La modernización y cambios en la industria jabonera española (1800-1914)», VII Simposio de Historia Económica, Barcelona, pp. 28-40.

SAinchez SuArez, A. (1987): «Los inicios del asociacionismo empresarial en España: La Real Compañia de Hilados de algodón de Barcelona, 1772-1820», Hacienda Pública Española, nums. 108-109, pp. 253-268. 
- (1988): La formación de una política económica probibicionista en Cataluña, 1760-1840, Espai/Temps, Lleida.

- (1989 a): "La era de la manufactura algodonera en Barcelona, 1736-1839», Estudios de Historia Social, núm. $48-49$, pp. $65-113$.

— (1989 b): «L'estructura comercial d'una fábrica d'indianas barcelonina: Joan Rull i Cía. (1790-1821)», Recèrques, 22, pp. 9-24.

- (1992): "La indianeria catalana: Mito o realidad», Revista de Historia Industrial, 1, Barcelona, pp. 213.232.

SEgARRa, A. (1988): LEconomia de Reus al segle xvin: el comerç de l'aiguardent, Reus.

Segura et alt (1991): El mon de la seda á Catalunya, Diputació, Barcelona.

Thompson, J. K. J. (1994): Els origens de la industrialització a Catalunya. El cotó a Barcelona (1728-1832), Edicions 62, Barcelona.

TORRas Elias, J. (1981): «Estructura de la industria precapitalista: La draperia», Reçerques, 11, pp. 7-28.

_- (1984): «Especialización agrícola e industria rural en Cataluña en el siglo Xvill», Revista de Historia Económica, núm. 3, pp. 113-127.

- (1987): «Fabricants sense fábrica. Estudi d'una empresa llanera d'Igualada (1726-1765)», Reçerques, núm. 19, pp. 145-160.

- (1990): «Las relaciones económicas entre Aragón y Cataluña antes del Ferrocarril», Actas del I Simposio sobre las relaciones económicas entre Aragón y Cataluña (siglos Xvill.xx), Instituto de Estudios Altoaragoneses, Huesca.

— (1992): «Gremio, familia y cambio económico. Pelaires y tejedores en Igualada (1695-1765)», Revista de Historia Industrial, 2, pp. 11-29.

— (1995): «Redes comerciales y auge textil en la España del siglo xviII", Mercados y manufacturas en Europa, pp. 111-132.

TORRas I RiBE, J. M. (1991): Curtidores y tenerias en Cataluña: Organización de un oficio preindustrial (siglos Xvi.xIX), Colomer Musnany, Vic.

- (1994): «La industria del curtido en Cataluña: Del trabajo manual al uso de la energia eléctrica", La cara oculta de la industrialización española, Alianza, Madrid, pp. 295-319.

VILAR, P. (1981): «La Cataluña industrial: Reflexiones acerca de un arranque y un destinow, La industrialización europea, Ed. Crítica, Barcelona, pp. 173-191. 


\section{APÉNDICE I}

Manufactura de lino/cáñamo

\begin{tabular}{|c|c|c|c|}
\hline Localidad & Telares & Empleo & $\begin{array}{l}\text { Producción } \\
\text { (piezas/año) }\end{array}$ \\
\hline Badalona . & * & 6 & 7.200 varas \\
\hline Cornella .. & 4 & * & * \\
\hline 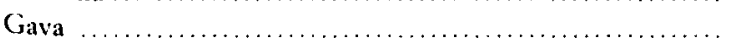 & $\therefore$ & 1 & * \\
\hline 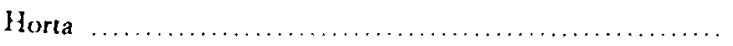 & 30 & * & * \\
\hline Hospitalet ............... & $*$ & 3 & $\stackrel{*}{\pi}$ \\
\hline Martorell ................ & 3 & * & 1.500 varas \\
\hline San Andrés del Palomar. & 5 & * & * \\
\hline San Feliu de Llobregat & $x^{*}$ & 4 & * \\
\hline Sarriá $\ldots \ldots \ldots \ldots \ldots \ldots$ & * & 3 & * \\
\hline Vallirana ................ & 2 & 1 & * \\
\hline Viladecans. & $*$ & 2 & * \\
\hline Baga $\ldots \ldots \ldots \ldots$ & 7 & * & * \\
\hline Berga $\ldots \ldots \ldots \ldots \ldots \ldots \ldots \ldots$ & 19 & 228 & 250 \\
\hline Cardona $\ldots \ldots \ldots \ldots \ldots$ & 20 & $*$ & 500 \\
\hline Pobla de Lillet ............. & 12 & * & * \\
\hline Solsona ................................. & 5 & * & 90 \\
\hline Calaf $\ldots \ldots \ldots$ & 2 & * & 20 \\
\hline Cervera $\ldots . . . . .$. & 37 & $*$ & * \\
\hline Guissona $1 \ldots \ldots \ldots \ldots \ldots$ & 36 & $*$ & 300 \\
\hline Oliana ............. & 7 & * & * \\
\hline Pons $\ldots \ldots \ldots \ldots \ldots \ldots \ldots$ & 35 & $*$ & * \\
\hline Santa Coloma de Queralt . & 6 & $*$ & 100 \\
\hline Tiurana $\ldots \ldots \ldots \ldots \ldots$ & 9 & * & * \\
\hline Tora $\ldots \ldots \ldots$ & 3 & 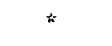 & * \\
\hline Mannesa $2 . . . . .$. & 167 & " & * \\
\hline Cardedeu ..... & 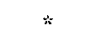 & 5 & * \\
\hline Mataro $\ldots \ldots \ldots \ldots$ & 52 & 52 & 1.392 \\
\hline San Andrés de Tona ... & 3 & 3 & * \\
\hline San Feliu de Torello .............. & 3 & $\Rightarrow$ & 25 \\
\hline San Quirce de Basora $\ldots . . \ldots \ldots \ldots \ldots \ldots \ldots \ldots$ & 22 & $\therefore$ & $*$ \\
\hline Ripoll $\ldots \ldots \ldots \ldots \ldots$ & 17 & 12 & 3 \\
\hline Taradell ........... & 4 & $\approx$ & 35 \\
\hline 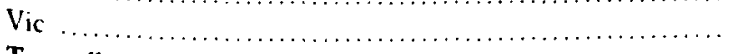 & 36 & 3.414 & * \\
\hline Torruella y Foix. & - & 1 & * \\
\hline Villafranca $\ldots . . .$. & 54 & 40 & * \\
\hline Amer ${ }^{1} \ldots$ & 3 & * & 25 \\
\hline La Bisbal & 52 & * & 1.400 \\
\hline Malgrat ................. & 8 & * & 30 \\
\hline 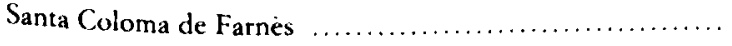 & 75 & * & 1.620 varas \\
\hline
\end{tabular}




\section{APÉNDICE I (continuación)}

Manufactura de lino/cáñamo

\begin{tabular}{|c|c|c|c|}
\hline Lacalidad & Telares & Empleo & $\begin{array}{l}\text { Producción } \\
\text { (piezas/año) }\end{array}$ \\
\hline San Feliu de Guixols. & - & 10 & * \\
\hline Tosa ................ & 2 & * & 20 \\
\hline $\mathbf{A l}_{\mathbf{p}} \ldots \ldots \ldots \ldots$ & * & 3 & * \\
\hline Seo de Urgell $\ldots \ldots \ldots \ldots \ldots \ldots \ldots$ & * & 9 & * \\
\hline Salas $\ldots \ldots \ldots \ldots \ldots \ldots$ & * & 75 & 3.000 canas \\
\hline Valls ............... & * & * & 1.108 \\
\hline Reus $\ldots \ldots \ldots \ldots$ & 105 & 1.275 & 5.760 \\
\hline Tarragona & & 39 & 28.000 canas \\
\hline
\end{tabular}

Notas: En negrita se inicia las localidades de cada una de las subdelegaciones. Las cifras co rresponden a los datos declarados, que son muy escasos por lo que a producción se refiere. En el empleo se incluyen hiladores en Berga, Reus y Vic, de ahi el engrosamiento de las cifras.

- La equivalencia era de 200 varas/pieza en Guisona, 40 canas/pieza en Amer y 56 varas/pieza en La Bisbal. (La vara equivale a $0,8356 \mathrm{~m}$. y la cana a $1,55 \mathrm{~m}$ )

2 La cantidad de telares corresponde a todo el corregimiento de Manresa.

3 Producia 170 canas a la semana.

Fuente: Censo de Manufacturas de 1784. 


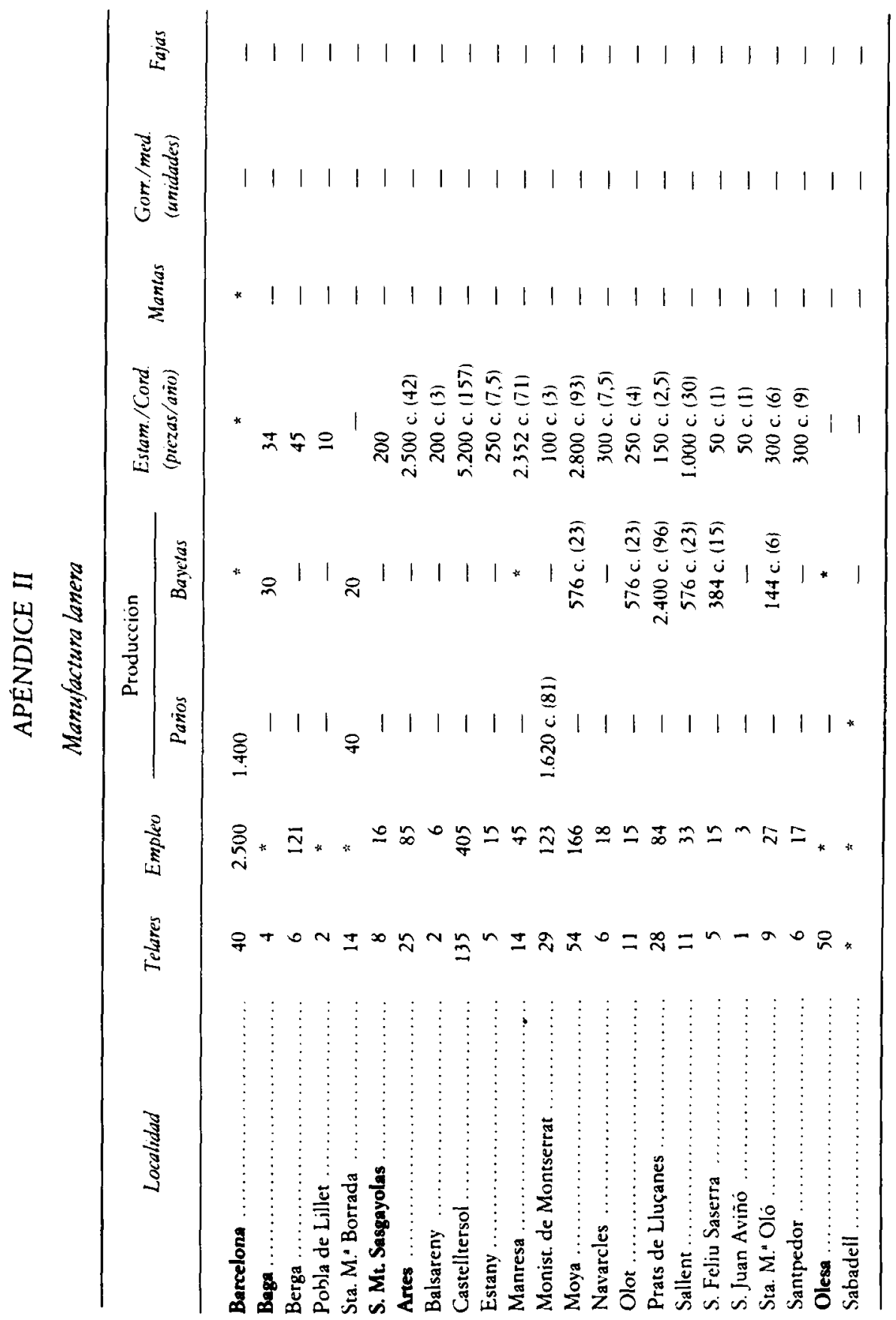




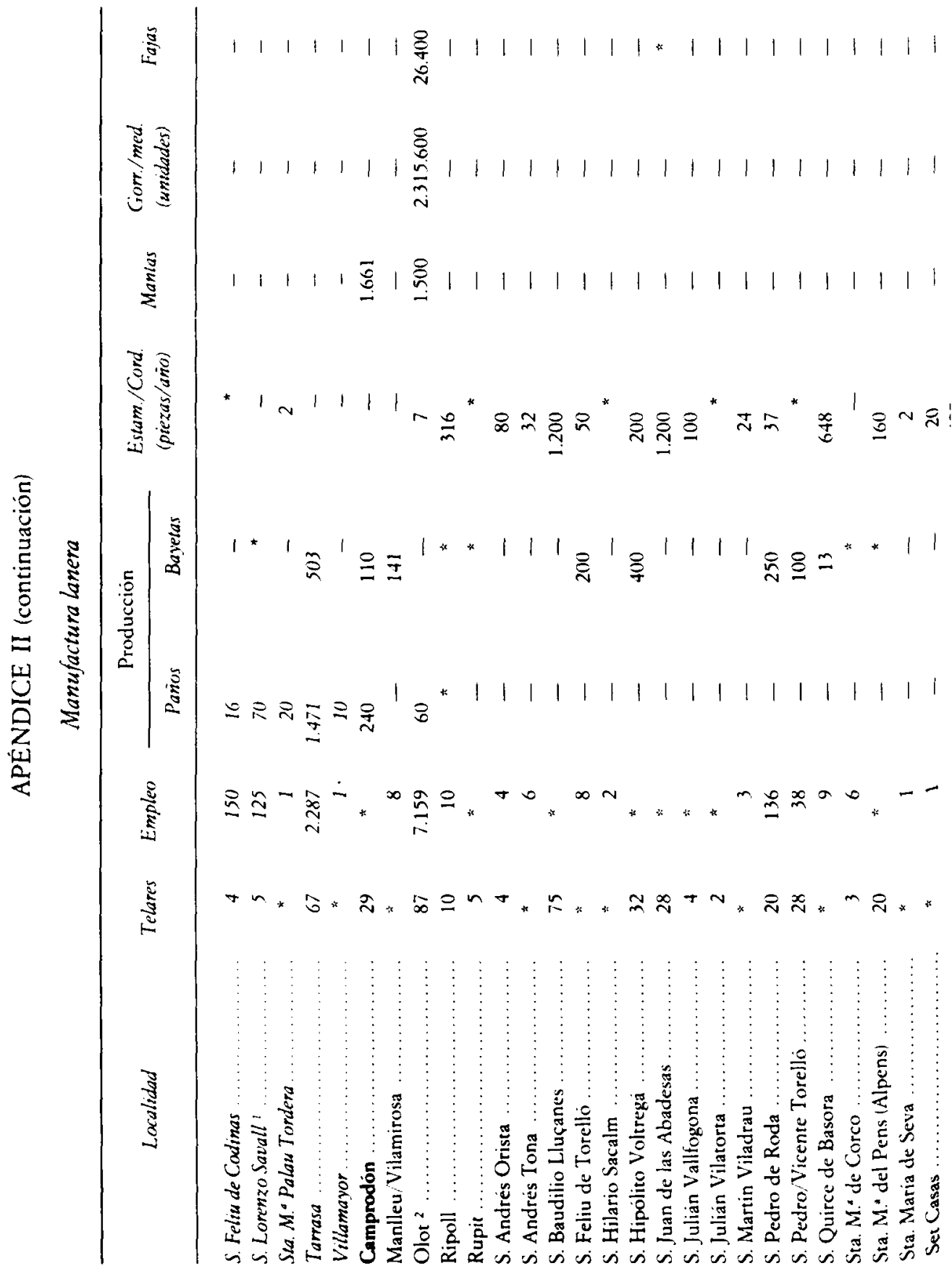




\section{APÉNDICE III}

Fabricación de sombreros

\begin{tabular}{|c|c|c|c|}
\hline Localidad & Fabricantes & Empleo & Producción/año \\
\hline Barcelona & 36 & 1.000 & 310.000 \\
\hline Igualada . & 6 & 190 & 48.000 \\
\hline Manresa & 3 & 6 & * \\
\hline Mataró ${ }^{1} \ldots \ldots \ldots \ldots$ & 3 & - & 2.400 \\
\hline Villafranca .............. & 2 & 4 & 2.304 \\
\hline Granollers .............. & 1 & - & 175 \\
\hline Cardedeu. & 1 & - & 125 \\
\hline Esparraguera & 1 & - & * \\
\hline 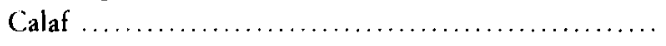 & 1 & - & * \\
\hline 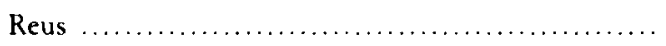 & 20 & - & 8.160 \\
\hline 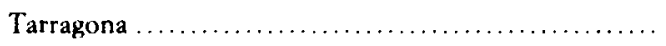 & 2 & - & 640 \\
\hline 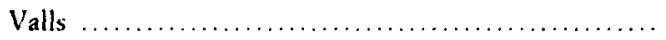 & 1 & - & 1.000 \\
\hline 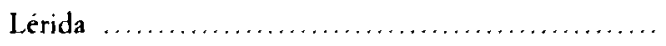 & 2 & - & * \\
\hline 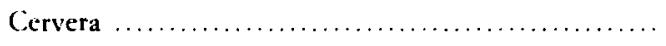 & 4 & - & * \\
\hline 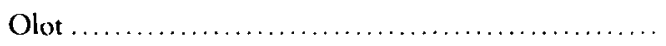 & 1 & 2 & 200 \\
\hline La Bisbal $\ldots \ldots \ldots \ldots \ldots \ldots \ldots \ldots \ldots \ldots \ldots \ldots \ldots \ldots \ldots \ldots \ldots \ldots \ldots \ldots \ldots$ & 2 & - & * \\
\hline
\end{tabular}

1 Los sombrereros de esta localidad eran Mariano Fargas, Andres Iglesias Mayor y Andrés Iglesias Menor, que obtenian 1.500, 300 y 600 sombreros al ano, respectivamente.

Fenve: Censo de Manufacturas de 1784 


\section{APÉNDICE IV}

Manufactura de seda

\begin{tabular}{|c|c|c|c|c|}
\hline Localidad & Producto & Telares & Empleo & Producción/año \\
\hline Barcelona & Medias & 900 & 2.500 & * \\
\hline Barcelona & Velos & 770 & 3.930 & $*$ \\
\hline Barcelona & Cordones & - & 1.800 & -1 \\
\hline Barcelona & Galones & 1.150 & 2.000 & * \\
\hline Manresa & Pañuelos & 667 & 810 & 839.832 unid. \\
\hline Manresa & Alafayas & - & - & 2.167 canas \\
\hline Manresa & Tafetanes & - & - & 2.037 canas \\
\hline Manresa & Galones & $128^{2}$ & 160 & 3.556 piezas \\
\hline Manresa & Cintas & - & 69 & 13.680 piezas \\
\hline Manresa & Cintas hiladillo & $140^{3}$ & 140 & 672.000 canas \\
\hline Manresa & Cordones & - & 12 & $\ddot{*}$ \\
\hline Mataró & Medias & 36 & * & 26.400 unid. \\
\hline Igualada & Pañuelos & 5 & 32 & 900 \\
\hline Igualada & Cintas & 3 & * & * \\
\hline Igualada & Cintas de gasas & 600 & * & * \\
\hline Reus & Pañuelos & 351 & 1.805 & 432.000 unid. \\
\hline Reus & Ropas & - & - & 14.400 canas \\
\hline Reus & Alafayas & - & 298 & 12.400 canas \\
\hline Reus & Cintas galón & - & - & 1.252 .800 canas \\
\hline Reus & Medias & 5 & $*$ & 2.200 unid. \\
\hline Valls & Fajas/ligas & 146 & * & 110.400 unid. \\
\hline Valls & Pañuelos & - & * & 6.000 unid \\
\hline Tarragona & Tafetan & * & $*$ & 6 piezas \\
\hline Tarragona & Tercianela & - & - & 1 piezas \\
\hline Tarragona & Espumillón & - & - & 3 piezas \\
\hline Tarragona & Pañuelos & - & - & 6 piezas \\
\hline Tarragona & Paño tafetán & - & - & 4 piezas \\
\hline Tortosa & Medias & 3 & $\star$ & 1.400 unid. \\
\hline Tortosa & Ropas & 16 & * & * \\
\hline Tortosa & Cintas & 21 & * & * \\
\hline Areyns de Mar & Blondas & - & * & $375 \mathrm{p}$ \\
\hline Areyns de Mar & Galones & - & 1 & 14 \\
\hline Areyns de Mar & Medias & $\star$ & 8 & 1.800 unid. \\
\hline Areyns de Mar & Mantillas & - & 10 & 2.400 unid. \\
\hline Areyns de Mar & Pañuelos & & & 5.400 unid. \\
\hline Calella & Medias & $\star$ & 21 & 7.600 unid. \\
\hline Calella & Encajes & - & $*$ & $4.800 \mathrm{p}$ \\
\hline Calella & Cordones & - & 7 & $119.660 \mathrm{p}$ \\
\hline Canet de mar & Pañuelos/gasa & $*$ & * & * \\
\hline Vic & Medias & $*$ & * & 1.200 unid. \\
\hline
\end{tabular}




\section{APÉNDICE IV (continuación)}

Manufactura de seda

\begin{tabular}{llccc}
\hline \multicolumn{1}{c}{ Lecalidad } & \multicolumn{1}{c}{ Producto } & Telares & Empleo & Producción/año \\
\hline Vic & Encaje & - & 900 & $*$ \\
Cardona & Pañuelos & 12 & 12 & $*$ \\
Granollers & Medias & 1 & $*$ & 720 unid. \\
Martorell & Medias & 4 & $*$ & 4 pares $/$ dia \\
Martorell & Galones & 2 & $*$ & $120 \mathrm{v}$ mes $/$ telar \\
Sallent & Pañuelos & 11 & 16 & 15.600 unid. \\
Santpedor & Pañuelos & 10 & 15 & 13.368 unid. \\
Sarriá & Medias & 3 & $*$ & $*$ \\
\hline
\end{tabular}

Nota: Las blondas de Areyns se obtenian en 80 almohadillas, además de realizarse 2.796 piezas de encaje de hilo en otras 1.100 almohadillas. En Calella disponia de 1.600 almohadillas para los encajes de seda indicados y producia otras 5.700 piezas en 1.900 almohadillas. En San Feliu de Guixol habia una fabrica de encajes de hilo que empleaba a 600 mujeres.

1 Se especifica en el cuadro 8 .

2 Habia otros 86 telares parados. Al igual que en la fabricación de cintas se encontraban 24 fabricas paradas y 57 corrientes.

Son de cuenta de Magin Valles.

Fuentr: Censo de Manufacturas de 1784.

\section{APÉNDICE V}

A) Manufactura algodonera (+ Lienzos pintados)

\begin{tabular}{lclccc}
\hline \multicolumn{1}{r}{ Localidad } & Fábricas & \multicolumn{1}{c}{ Producto } & Telares & Empleo & Producción(Piezas/año) \\
\hline Barcelona & 80 & Indianas & 2.452 & 8.638 & 273.600 \\
Barcelona & - & Lienzos pintados & - & - & 161.750 \\
Manresa & 1 & Indianas & 25 & 174 & 2.652 \\
Manresa & - & Pañuelos & 51 & 174 & 2.652 \\
Vic & 1 & Tejidos lino/algo- & & & \\
& & dón & - & 40 & 1.500 \\
Vic & 2 & Indianas & 23 & 425 & 1.250 \\
Vic & - & Muselinas & - & - & 750 \\
Igualada & 18 & Indianas & 136 & 300 & 5.200 \\
Igualada & - & Pañuelos & - & - & 14.400 unidades \\
Igualada & - & Terciopelo & 2 & - & 32 \\
Igualada & - & Cotonías & 2 & - & 75 \\
Mataro & 2 & Indianas & 117 & 475 & 12.000 \\
Mataró & - & Pañuelos & 10 & - & 500 \\
Mataró & - & Lienzo pintado & - & - & 9.000 \\
Mataró & - & Pañuelos hilo china & & & \\
& & pintados & - & - & 25.000 \\
Mataro & 1 & Estopillas & 12 & 26 & 1.100 \\
Berga & 8 & Tejidos & 58 & 852 & 2.736 \\
Capellades & 17 & Tejidos & 58 & 384 & 1.536 \\
Manlleu & - & Tejidos & 51 & - & 1.450
\end{tabular}




\section{APÉNDICE V (continuación)}

A) Manufactura algodonera (+ Lienzos pintados)

\begin{tabular}{lclccc}
\hline \multicolumn{1}{c}{ Localidad } & Fabricas & \multicolumn{1}{c}{ Producto } & Telares & Empleo & Praducción(Piezas/año) \\
\hline Olot & 1 & Indianas & 14 & 60 & 1.456 \\
Olot & 1 & Muselinas & 16 & 30 & 300 \\
Villamayor & - & Tejidos & 4 & - & 290 \\
Esparaguera & 1 & Tejidos & 2 & - & 80 \\
Prats de Rei & 1 & Tejidos & 9 & - & 500 \\
San Feliu de Torello & 1 & Tejidos & 7 & - & 125 \\
San Martin Sasgay & - & Tejidos & 4 & - & 42 \\
San Quinti & - & Tejidos & 3 & - & 100 \\
Sarria de Ter & 1 & Cotonias & 5 & $*$ & $*$ \\
Tortella & 1 & Indianas & - & 700 & 2.000 \\
Valls & 11 & Tejidos lino/algo- & & & \\
& & doin & - & - & 2.733 \\
Arenys de Mar & - & Cotonias & $*$ & 26 & 625 \\
Cardedeu & - & Tejidos & 1 & 1 & $*$ \\
Tosa & - & Cotonias & 2 & - & 20 \\
\hline
\end{tabular}

Nola: Ademas se teje, aunque no se aportan, cantidades en Santa Maria Palau Tordera, San Celoni, Olesa, Martorell y Castellar. En Berga se incluyen tejedores, cardadores e hilanderas en el dato de empleo.

B) Otros productos de algodón

\begin{tabular}{lclrcc}
\hline \multicolumn{1}{c}{ Localidad } & Fíbricas & Producto & Telares & Empleo & $\begin{array}{c}\text { Producción } \\
\text { (Unidades/año) }\end{array}$ \\
\hline Vic & 1 & Medias & 13 & 400 & 6.000 \\
Igualada & - & Medias & 6 & $*$ & $*$ \\
Mataró & 1 & Medias & 24 & $*$ & 36.000 \\
Olot & 39 & Medias/gorros & 500 & 1.150 & 611.520 \\
Puigcerda & - & Gorros/medias & 82 & 200 & 98.400 \\
Ripoll & 1 & Medias/gorros & 8 & $*$ & 7.200 \\
San Feliu de Guixols & 1 & Medias & 25 & $*$ & 6 medias/telar/dia \\
San Feliu de Palla. & & & & & $*$ \\
$\quad$ rols & - & Medias & 8 & $*$ & $*$ \\
San Juan de las Aba- & & & & & \\
$\quad$ desas & 1 & Medias & 12 & $*$ & 6.000 \\
Tortella & 3 & Medias & $*$ & 57 & 39.000 \\
Seo de Urgell & 1 & Medias & 30 & 180 & 18.000 \\
Areyns de Mar & 3 & Medias & $*$ & 10 & 8.328 \\
Calclla & 2 & Medias & $*$ & 62 & 51.600 \\
\hline
\end{tabular}

Funite: Censo de Manufacturas de 1784 
APÉ

Encla

\begin{tabular}{|c|c|c|c|c|c|}
\hline \multirow{2}{*}{ Localidad } & \multirow{2}{*}{ Fble. } & \multirow{2}{*}{ Tenerias } & \multirow{2}{*}{ Empleo } & \multicolumn{2}{|c|}{ Producción (Piezas/año) } \\
\hline & & & & Suela & Badan \\
\hline Barcelona (1) ............ - & & 62 & 201 & 49.500 & $78.60 \mathrm{C}$ \\
\hline Manresa $\ldots \ldots \ldots \ldots \ldots \ldots$ & - & 3 & 6 & - & - \\
\hline Vic $\ldots \ldots \ldots \ldots \ldots \ldots \ldots$ & 21 & - & - & 1.000 & 1.200 \\
\hline Igualada $\ldots \ldots \ldots \ldots \ldots \ldots$ & 92 & 14 & - & 24.000 & - \\
\hline Horta $(1) \ldots \ldots \ldots \ldots \ldots$ & 1 & 1 & 80 & 8.000 & - \\
\hline Mataró (2) $\ldots \ldots \ldots \ldots \ldots$ & 8 & - & - & * & - \\
\hline Villafran. . .............. & - & 8 & 16 & * & * \\
\hline Granollers $\ldots \ldots \ldots \ldots \ldots$ & - & 2 & - & $=$ & * \\
\hline Areyns de Mar $\ldots \ldots \ldots \ldots$ & - & 1 & 3 & 140 & - \\
\hline Calella $\ldots \ldots \ldots \ldots \ldots \ldots$ & - & 1 & 2 & 300 & - \\
\hline Olot $\ldots \ldots \ldots \ldots \ldots$ & - & 19 & 125 & 8.000 & $-\cdots$ \\
\hline La Bisbal . ................ & - & 9 & * & - & * \\
\hline Ripoll $\ldots \ldots \ldots \ldots \ldots \ldots$ & - & 5 & - & $\approx$ & - \\
\hline S. C. de Capdevañ. . ....... & - & 2 & - & - & - \\
\hline S. Feliu de Guixols . ........ & - & 1 & - & * & - \\
\hline Palafrugell $\ldots \ldots \ldots \ldots \ldots$ & - & 1 & - & $*$ & - \\
\hline Reus (3) $\ldots \ldots \ldots \ldots \ldots \ldots$ & 70 & - & - & - & 1.200 \\
\hline Valls $\ldots \ldots \ldots \ldots \ldots \ldots$ & - & 11 & - & - & - \\
\hline Tortosa $(4) \ldots \ldots \ldots \ldots \ldots$ & 2 & 2 & - & - & 280 \\
\hline Xerta (5) $\ldots \ldots \ldots \ldots \ldots$ & 1 & 1 & - & $\hbar$ & $*$ \\
\hline Sta. Coloma Queralt ...... & -- & 1 & - & * & $*$ \\
\hline Salas $\ldots \ldots \ldots \ldots \ldots \ldots$ & - & 3 & 400 & 1.200 & 720 \\
\hline Oliana $\ldots \ldots \ldots \ldots \ldots \ldots$ & - & 1 & - & * & * \\
\hline Lérida $\ldots \ldots \ldots \ldots \ldots \ldots$ & - & - & - & - & * \\
\hline
\end{tabular}

Nota: En Barcelona se han sumado los datos de curtidores y zurradores, que, ademas de lo expues ros, 11.000 pieles de cabra y 10.000 de carnero. En Mataro, 8.000 cueros al pelo. En Manresa se trabaja

(1) El empresario es Jose Alvareda.

(2) Los fabricantes identificados tienen por razón social: Compañia de José y Antonio Vilardevo, Cor Jaime Vilardevo, Rafacl Estaper, José Jalencas.

(3) En Reus se anotan también 94 zapateros que consumen 840 docenas de curtidos y obtienen 384

(4) Se trata de los empresarios Salvador Zaragoza y Mateo Sabater.

(5) El fabricante es Juan Bautista Damare.

Ftente: Censo de Manufacturas de 1784. 


\section{ICE VI}

de curtido

\begin{tabular}{|c|c|c|c|c|c|c|}
\hline Cordobin & Baqueta & Gamuza & Ante & Becerrillo & Pergamino & Corregel \\
\hline 52.200 & 16.467 & - & - & 50.800 & 48.000 & $\ldots$ \\
\hline- & $\begin{array}{r}10.401 \\
-\end{array}$ & - & .. & - & 40.000 & - \\
\hline & - & 147.000 & - & - & - & - \\
\hline 21.000 & 2.000 & 141.000 & - & - & - & - \\
\hline 24.000 & 1.000 & 72.000 & 2.000 & 12.000 & .. & - \\
\hline * & * & * & - & * & * & - \\
\hline * & * & * & * & * & - & - \\
\hline * & - & - & - & - & _- & \\
\hline 250 & - & - & - & - & - & - \\
\hline * & - & - & - & * & - & - \\
\hline 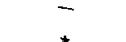 & 64.000 & - & - & 3.800 & 3.600 & 3.000 \\
\hline * & * & - & - & * & - & \\
\hline " & * & * & - & - & - & - \\
\hline 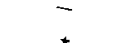 & - & - & - & - & -- & - \\
\hline * & * & - & - & - & - & -.- \\
\hline${ }^{*}$ & * & - & - & - & - & - \\
\hline 3.600 & - & -- & - & - & - & - \\
\hline- & - & - & - & - & - & - \\
\hline $\begin{array}{r}1.680 \\
*\end{array}$ & 2.400 & 120 bald & - & - & - & - \\
\hline$*$ & $*$ & - & - & * & - & $\ldots$ \\
\hline * & - & - & - & _- & - & .- \\
\hline 100 & - & -- & - & - & - & \\
\hline$*$ & - & - & - & - & - & - \\
\hline * & * & * & - & - & - & - \\
\hline
\end{tabular}

obtienen 19.000 salefas, 18.000 cabritillas, 3.000 guarnimenteras y 4.750 colas. En Valls trabajan 16.000 cue ${ }^{69}$ quintales; en La Bisbal, 700 quintales por 7 de las 9 fábricas, y en Tortosa, 25 quintales.

ñia de Tomás Fabres, Compañia de Pedro Blanco y Saturnino Masanes, Ramón Lacroy, Francisco Vilardevo, zapatos. 
La Riba

Alfara

Plana y Samunta

Seguer

Torre de Claramunt

Capellades

San Pedro Riudevitlles

Manlleu/Vilamirosa

San Quinti

Carme

San Pedro de Roda

Manresa

Sabadel]

Villanueva de Cami

Torruella y Foix

San Sadurni

San Celoni

Suria (1)

San Esteban Palau Tordera

Barberá

Ripollet

Olot .

S. Martin de Viladrau

Ripoll

Lérida

Pons
26

1

1

1

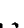

12

5

3

2

2

2

2

1

1

1

1

1

1

1

2

5

2

1

2

1
Bellet/Escribano/Sabater/Castillo

José Serra

Juan Marañosa

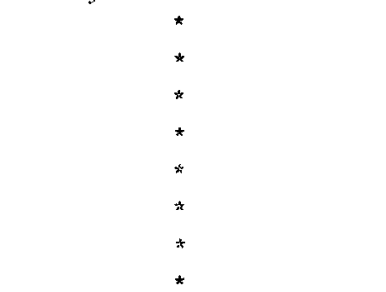

Frco. Capela/Teresa Arderiu José 'Toralló (Igualada)

Pedro Mir y Ros

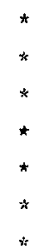

Francisco Coll

En construccion

Nota: Ademas tenian un molino en San Feliu de Torello, San Vincenc dels Horts, Martorell ( 4 tinas)

(1) En Suria habia otro molino sin uso.

(2) De las resmas indicadas 500 son de papel florete.

FufNTE: Censo de Manufacturas de 1784. 


\section{ICE VII}

ra papelera

Praducción (Resmas/año)
Empleo Papel blanco

Cartones

$+39$

390

14

15

100

252

150

$-$

18

10

16

8

$-$

5

14

--

$-$

$-$

$-$

200 quint.

90

$-$

-

51.600

$$
1.800
$$

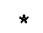

$*$

$\begin{array}{lc}- & * \\ - & - \\ - & - \\ - & - \\ * & - \\ - & 20.000 \\ 700 & - \\ - & - \\ 4.000 & - \\ - & -\end{array}$

4.000

1.400

2.190

3.000

1.000

6.000

2.000

$1.000(2)$

2.160

6.480

$-$

$-$

$-$

*

$-$

$-$

$-$

200 quint.

$-$

$-$

$-$

$-$

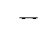

250 quint

250 quint

dona y Copons. En la Riba 23 de los 26 molinos son de papel blanco y en San Pedro Riudevitlles lo son nueve. 


\begin{tabular}{|c|c|c|c|}
\hline \multicolumn{4}{|c|}{$\begin{array}{c}\text { Apéndice VIII } \\
\text { Fabricación de loza }\end{array}$} \\
\hline Localidad & N." establecim. & Propiedad & Empleo \\
\hline S. Juliān de Vilatorta . & 15 & - & 36 \\
\hline Canet de Mar ......... & 1 & - & - \\
\hline Copellades $\ldots . . . \ldots \ldots$ & 1 & - & 3 \\
\hline Ripoll $\ldots \ldots \ldots \ldots \ldots \ldots$ & 1 & Jaime Taulez & - \\
\hline Lérida $\ldots . . . \ldots \ldots \ldots \ldots$ & 9 & - & - \\
\hline Reus $\ldots \ldots \ldots \ldots \ldots \ldots$ & 11 & - & - \\
\hline
\end{tabular}

Fuente: Censo de Manufacturas de 1784. 


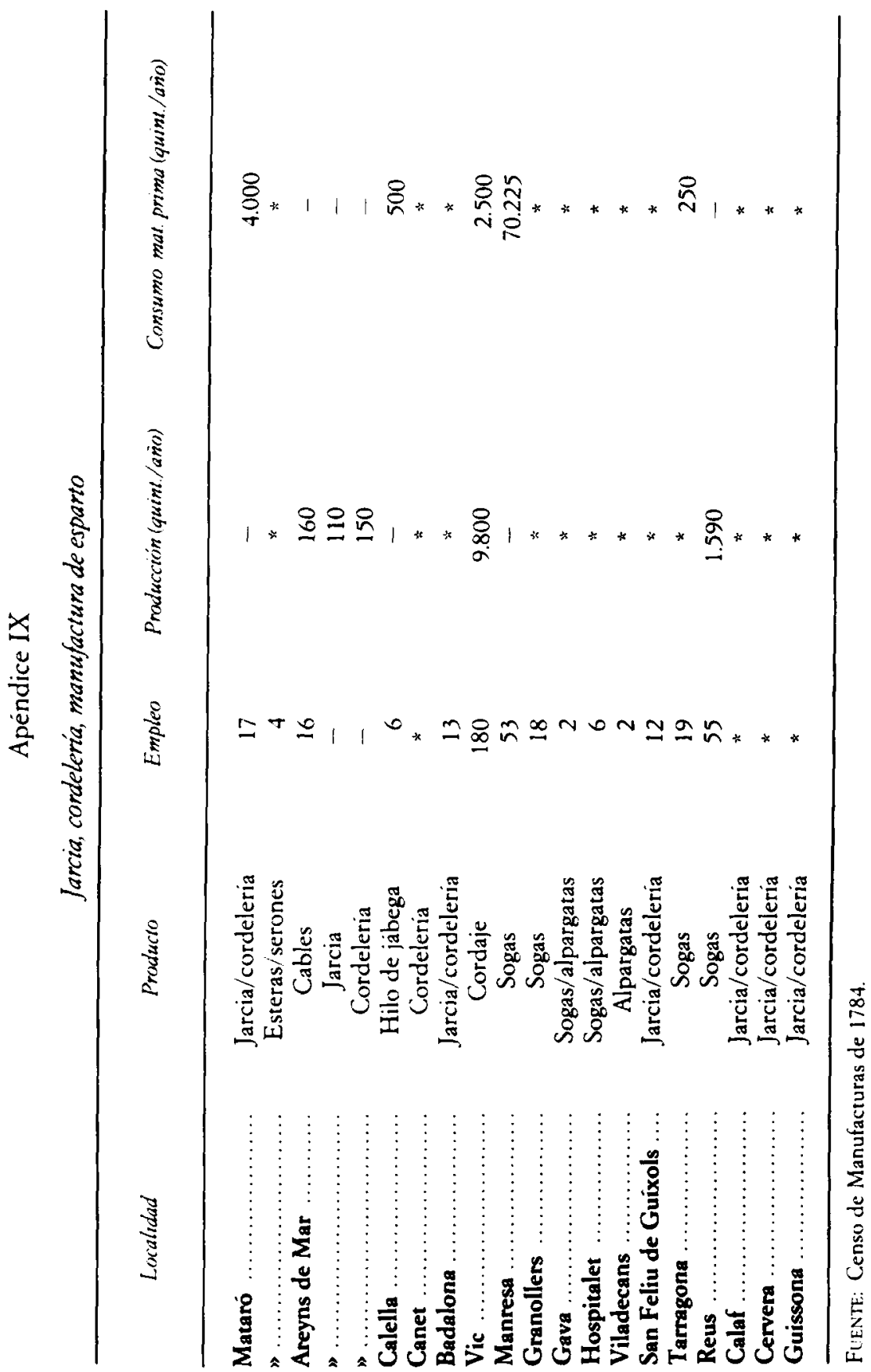


Apéndice X

Actividad jabonera

\begin{tabular}{|c|c|c|c|c|}
\hline Localidad & Calderas & Propietario & $\begin{array}{l}\text { Producción } \\
\text { Jaboin duro }\end{array}$ & $\begin{array}{l}\text { (Quintales/anio) } \\
\text { Jabón blandos }\end{array}$ \\
\hline Reus $\ldots \ldots \ldots \ldots \ldots$ & 7 & -- & - & 2.400 \\
\hline Tortosa ........... & 5 & - & - & 1.698 \\
\hline$" \ldots \ldots \ldots \ldots \ldots$ & 1 & José Ferrer Santa Fe & 400 & - \\
\hline$\$ \ldots \ldots \ldots \ldots \ldots$ & 1 & Diego Martinez & 144 & $\ldots$ \\
\hline Xerta $\ldots \ldots \ldots \ldots$ & 1 & Miguel Rabañals & 300 & - \\
\hline$\$ \ldots \ldots \ldots \ldots \ldots \ldots$ & 1 & Andrés Vidal & 700 & $\cdot-$ \\
\hline$n \ldots \ldots \ldots \ldots \ldots$ & 1 & Manuel Barbera & - & 37,5 \\
\hline$» \ldots \ldots \ldots \ldots \ldots \ldots$ & 1 & José Antonio Mola & - & 37,5 \\
\hline Mora de Ebro .... & 1 & Mariano Valls & 37,5 & - \\
\hline$\$ \ldots \ldots \ldots \ldots \ldots$ & 1 & José Antonio Montagut & 25 & \\
\hline Tarragona ........ & 1 & Juan lómás & - & 750 \\
\hline$\nabla \ldots \ldots \ldots \ldots \ldots$ & 1 & Francisco Martorell & - & Parada \\
\hline Olot $\ldots \ldots \ldots \ldots$ & 4 & - & 15 & 3.000 \\
\hline Mataró $\ldots \ldots \ldots . .$. & 2 & Salvador Issart & 2.000 & \\
\hline$\$ \ldots \ldots \ldots \ldots \ldots$ & 2 & Mariano Trissach & 2.000 & \\
\hline Areyns de Mar ... & 2 & - & 610 & - \\
\hline Igualada $\ldots \ldots \ldots$ & 1 & $-\cdot$ & 75 & - \\
\hline Lérida $(*) \ldots \ldots \ldots$ & 5 & - & - & - \\
\hline Tora $\ldots \ldots \ldots \ldots$ & 1 & - & Parada & - \\
\hline Cervera...$\ldots \ldots$. & 1 & & Parada & - \\
\hline Tremp ............ & 1 & $\cdot \cdot$ & 50 & \\
\hline Tiurana ........... & 1 & - & Parada & - \\
\hline Solsona ........... & 1 & - & - & - \\
\hline Arbeca $\ldots \ldots \ldots \ldots$ & varias & - & $*$ & \\
\hline Borjas Blancas ... & varias & - & * & .. \\
\hline
\end{tabular}

(*) Solo una trabajaba continuamente

Firive: Censo de Manufacturas de 1784 


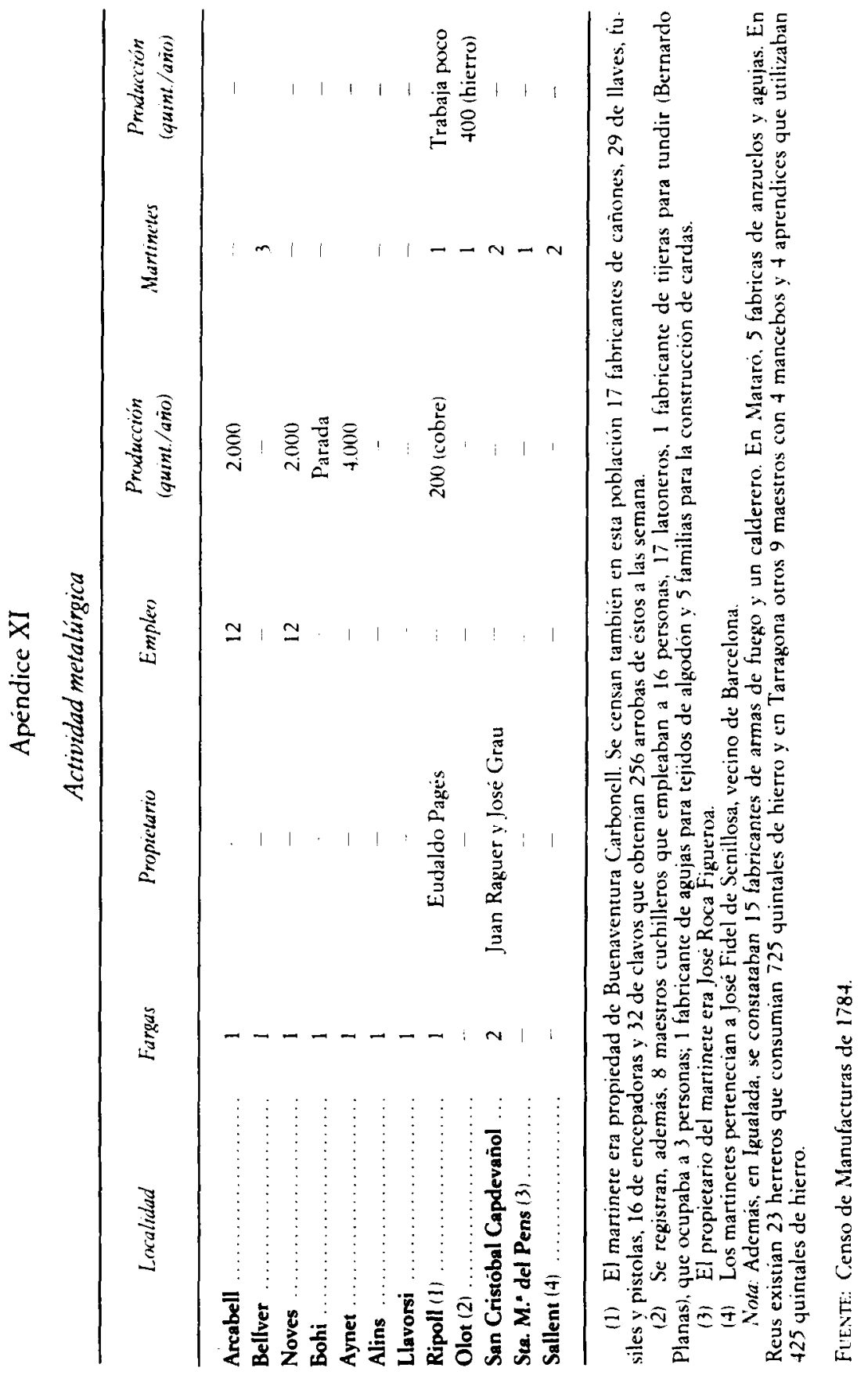




\section{Apéndice XII}

Fabricación de aguardiente

\begin{tabular}{|c|c|c|c|}
\hline Localidad & Fábricas & Empleo & Producción (arrobas/año) \\
\hline Artes...................... & 1 & 3 & 27.375 \\
\hline Capellades ................... & 2 & 2 & * \\
\hline Castelladrall .................. & 1 & 3 & 27.375 \\
\hline Castellfollit ................... & 1 & 3 & 27.375 \\
\hline Castellar y Quadras ......... & 1 & 3 & 27.375 \\
\hline Castellbell ...................... & 4 & 12 & 109.500 \\
\hline Castellet ..................... & 1 & 3 & 27.375 \\
\hline Guardiola .................... & 4 & 12 & 109.500 \\
\hline Manresa.................. & 9 & 25 & 246.375 \\
\hline Marganell .................... & 3 & 9 & 82.125 \\
\hline Monistrol de Calders ........ & 2 & 6 & 54.750 \\
\hline Monistrol de Monserrat .... & 1 & 3 & 27.375 \\
\hline Mura ......................... & 3 & 9 & 82.125 \\
\hline Navarcles ..................... & 3 & 9 & 82.125 \\
\hline Olivellas ...................... & 1 & 3 & 27.375 \\
\hline 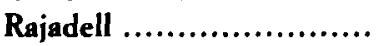 & 2 & 6 & 94.750 \\
\hline Sallent ....................... & 6 & 18 & 164.250 \\
\hline San Iscle ...................... & 1 & 3 & 27.375 \\
\hline San Fructuoso de Bages .... & 1 & 3 & 27.375 \\
\hline Santpedor ..................... & 6 & 18 & 164.250 \\
\hline Talamanca ..................... & 2 & 6 & 54.750 \\
\hline Turruella .................... & 2 & 6 & 54.750 \\
\hline Villaformosa ................. & 1 & 3 & 27.375 \\
\hline Villatorrada .................. & 1 & 3 & 27.375 \\
\hline Igualada (1) .................. & 8 & $\div$ & $*$ \\
\hline 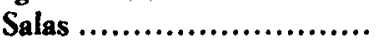 & 8 & * & * \\
\hline Reus ........................... & 80 alamb. & - & * \\
\hline Tortosa ........................ & 1 & - & Parada \\
\hline
\end{tabular}

(*) Distribuidas por la villa, Villanueva, Odena y Mombuy

Finnie: Censo de Manufacturas de 1784. 


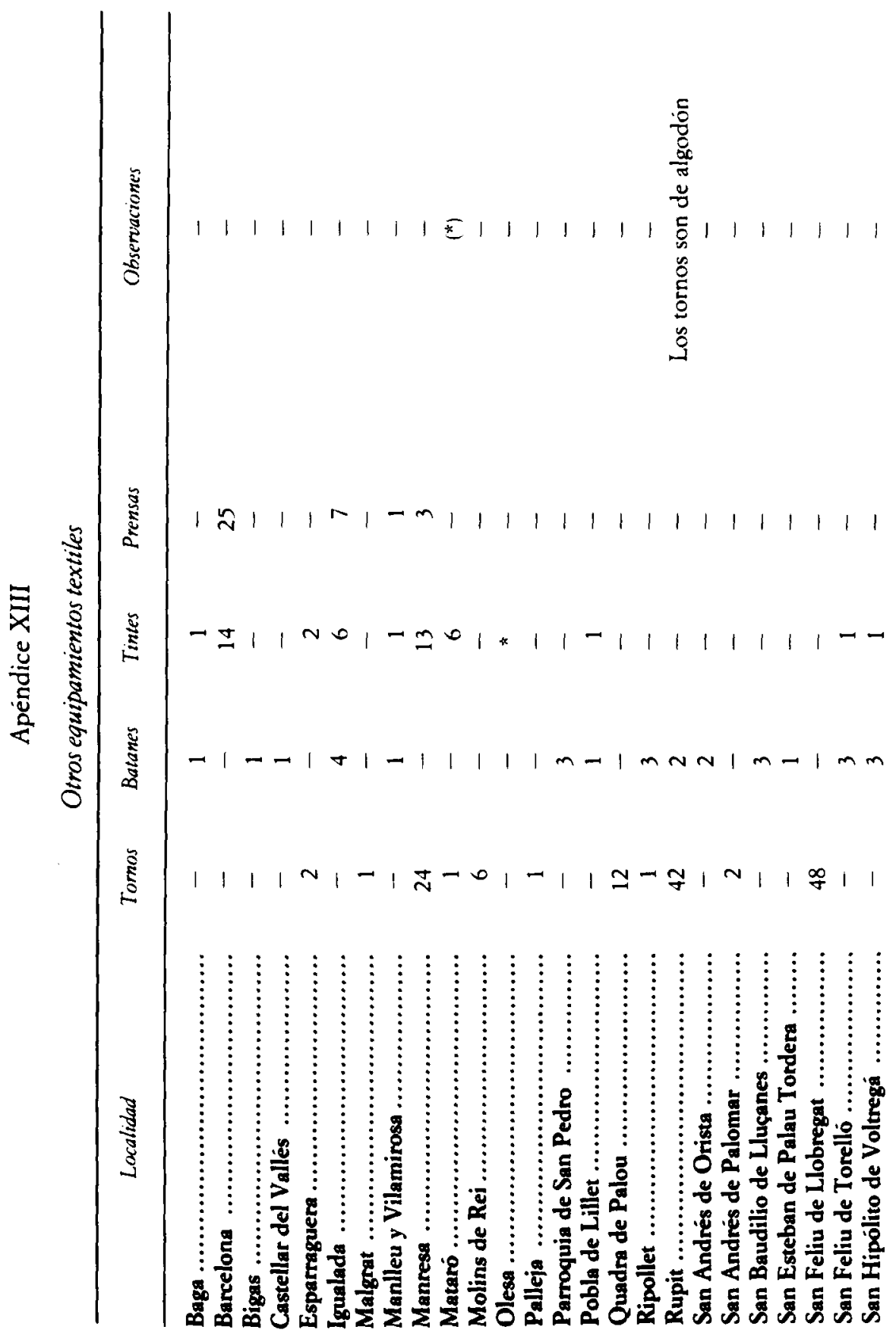




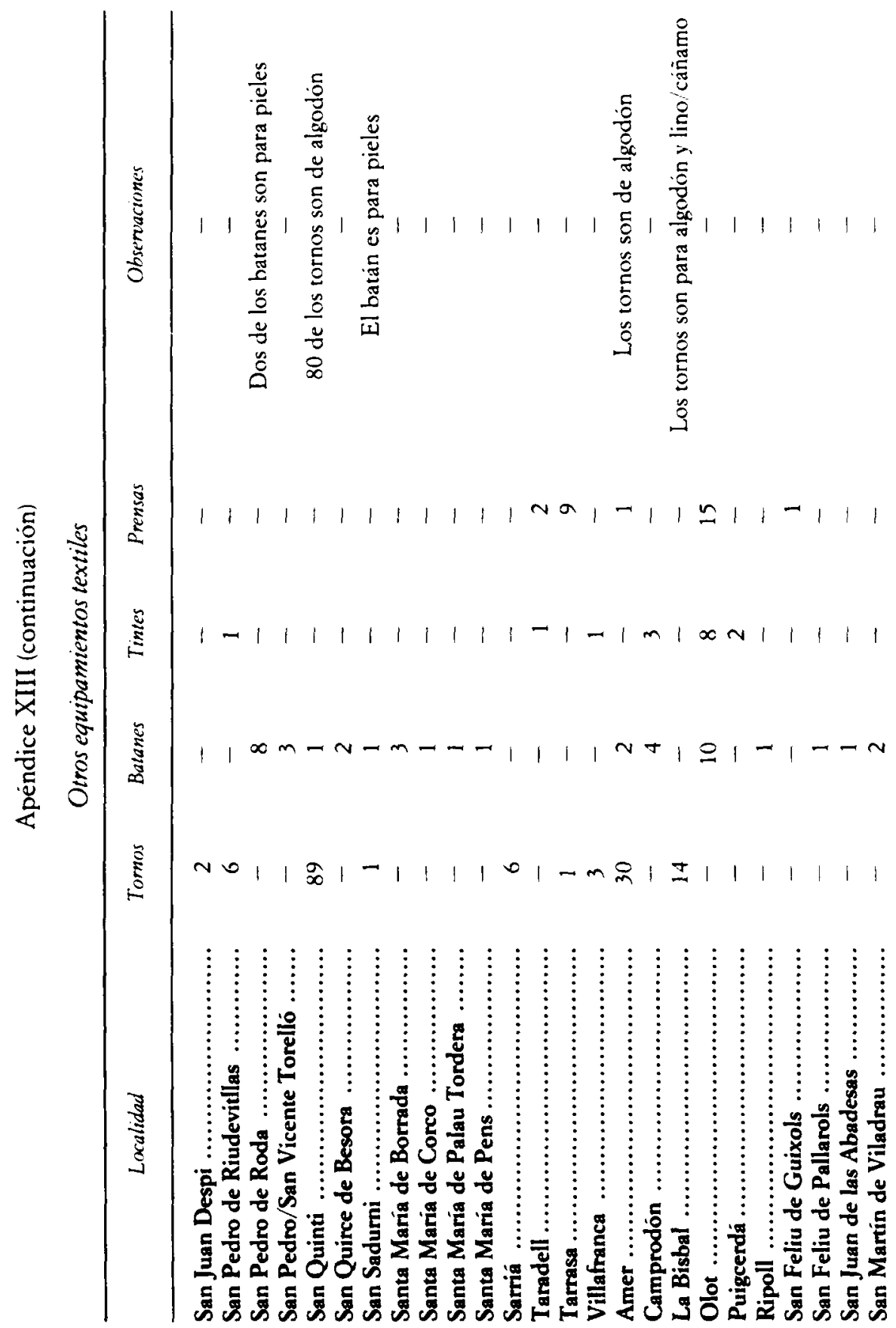




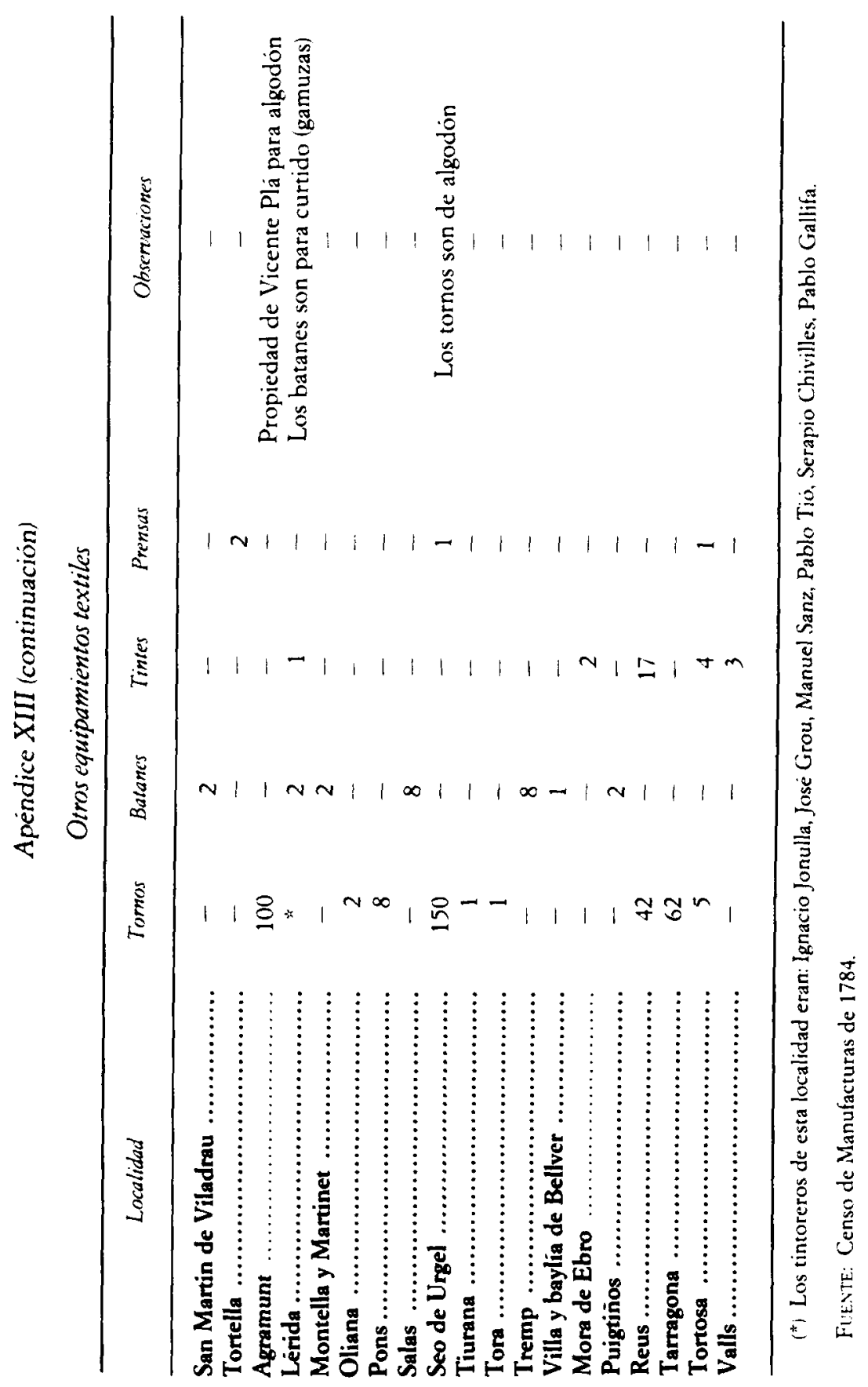

